\title{
PRIORITIZATION OF THE LAUNCH OF ICT PRODUCTS AND SERVICES THROUGH LINGUISTIC MULTI-CRITERIA DECISION-MAKING
}

\author{
Andrés CID-LÓPEZ ${ }^{1}$, Miguel J. HORNOS ${ }^{1}$, \\ Ramón A. CARRASCO-GÓNZÁLEZ², Enrique HERRERA-VIEDMA ${ }^{3,4 *}$ \\ ${ }^{1}$ Department of Software Engineering, University of Granada, Granada 18071, Spain \\ ${ }^{2}$ Department of Marketing and Market Research, Complutense University of Madrid, \\ Madrid 28015, Spain \\ ${ }^{3}$ Department of Computer Science and Artificial Intelligence, University of Granada, \\ Granada 18071, Spain \\ ${ }^{4}$ Department of Electrical and Computer Engineering; King Abdulaziz University, \\ Jeddah 21589, Saudi Arabia
}

Received 04 May 2017; accepted 10 February 2018

\begin{abstract}
The market launch of new products and services is a basic pillar for large and mediumsized companies in the ICT (Information and Communications Technology) sector. Choosing the right moment for it is usually a differentiating factor in terms of competition, since it is a source of competitive advantage. There are several mechanisms and strategies to address this problem from the market perspective. However, the criteria of the different actors involved - managers, sales representatives, experts, etc. - coexist in the corporate sphere and they often differ, causing difficulties in priority setting processes in the launch of a product or service. The assessment of the prioritization of these criteria is usually expressed in natural language, thus adding a great deal of uncertainty. Fuzzy linguistic models have proved to be an efficient tool for managing the intrinsic uncertainty of this type of information. This paper presents a linguistic multi-criteria decision-making model, able to reconcile the different requirements and viewpoints existing in the corporate sector when planning the launch of new products and services. The proposed model is based on the fuzzy 2-tuple linguistic model, aimed at managing linguistic data expressing different corporate criteria, without compromising accuracy in the calculation of said data. In order to illustrate this, a practical case study is presented, in which the model is applied for scheduling the launch prioritization of several new products and services by a telecommunications company, within the deadlines set in its strategic planning.
\end{abstract}

Keywords: Strategic planning, linguistic multi-criteria decision-making, 2-tuple representation, launch of products/services, project prioritization, ICT sector.

JEL Classification: D81, M11, M15, O21, O32, L86.

*Corresponding author. E-mail: viedma@decsai.ugr.es

This is an Open Access article distributed under the terms of the Creative Commons Attribution License (http://creativecommons. org/licenses/by/4.0/), which permits unrestricted use, distribution, and reproduction in any medium, provided the original author and source are credited. 


\section{Introduction}

As is well-known, products and services have a mainly strategic nature for enterprises. Therefore, the most appropriate moment for their launching on the market must be planned with sufficient time in advance (Bharadwaj, El Sawy, Pavlou \& Venkatraman, 2013; Kahn, Barczak, Nicholas, Ledwith, \& Perks, 2012; Kaplan \& Norton, 2001). In this sense, choosing the perfect timing for the launch of each product/service is normally a differentiating aspect in terms of competition, since it is a source of competitive advantage (Barney, 2014). Generally, the launch schedule for new products or services is set out in a company's strategic planning. There are several mechanisms and strategies to address this problem from the market perspective, which are discussed in the papers written by Bryson (2011), Goetsch and Davis (2014) and Meyr, Wagner, and Rohde (2015), among other articles of the specialized literature on this topic.

Given the importance of a proper scheduling in the launch of a company's products and services, several criteria must be taken into account in the decision-making process, as described in the studies authored by Allen (2015), Calantone and Di Benedetto (2012) and Winter and Sundqvist (2009), among others. Obviously, the participation of different actors belonging to different departments (marketing, finance, production, etc.) of the company in this process, with different views about prioritization in the launch of new products and services, makes planning very complex and causes organizational tensions (Benedetto, 1999; Debruyne et al., 2002; Kapferer, 2012). This process can become even more complex due to the fact that all the different criteria are normally expressed in natural language, which entails a significant inaccuracy and uncertainty.

Multi-criteria decision-making (MCDM) models have been used to solve discrete problems using a wide variety of methods (Tzeng \& Huang, 2011), among which we can mention the following ones: Scoring methods, such as SAW (Simple Additive Weighting) and COPRAS (COmplex PRoportional ASsessment); Distance-based methods, such as VIKOR (VIsekriterijumska optimizacija i KOmpromisno Resenje) and TOPSIS (Technique for Order of Preference by Similarity to Ideal Solution); Pairwise comparison methods, such as AHP (Analytic Hierarchy Process) and ANP (Analytic Network Process); Outranking methods, such as PROMETHEE (Preference Ranking Organization METHod for Enrichment Evaluation) and ELECTRE (ELimination Et Choix Traduisant la REalité).

Due to the nature of the problems we want to solve, our proposal is made up of a combination based on scoring methods with additional elements of fuzzy linguistic and 2-tuple models (Herrera \& Martínez 2001, 2000a). A justification of the choice of this type of MCDM methods for the problem addressed here is presented in Appendix 1, where some of the most widespread existing MCDM models are compared.

Fuzzy linguistic models have proved to be an effective tool for managing the intrinsic uncertainty of this type of data, as reported by Cabrerizo, Herrera-Viedma, and Pedrycz (2013), Cabrerizo, Ureña, Pedrycz, and Herrera-Viedma (2014), Massanet, Riera, Torrens, and Herrera-Viedma (2014), Morente-Molinera, Pérez, Ureña, and Herrera-Viedma (2015), MorenteMolinera, Mezei, Carlsson, and Herrera-Viedma (2017) and Pérez-Asurmendi and Chiclana (2014), among others. These linguistic models have also been successfully applied to different 
problems related to MCDM in industry, among which we can cite the studies carried out by Carrasco, Sánchez-Fernández, Muñoz-Leiva, Blasco, and Herrera-Viedma (2015), Carrasco, Muñoz-Leiva, Sánchez-Fernández, and Liébana-Cabanillas (2012), Carrasco, Villar, Hornos, and Herrera-Viedma (2011), Cid-López, Hornos, Carrasco, Herrera-Viedma, and Chiclana (2017), Cid-López, Hornos, Carrasco, and Herrera-Viedma (2016, 2015a, 2015b), Liao and Xu (2015), Martínez-Cruz, Porcel, Bernabé-Moreno, and Herrera-Viedma (2015), Wang, J., Wang, J. Q., Tian, and Zhao (2017), Wang, Peng, Zhang, Liu, and Chen (2015), Wu, Chiclana, and Herrera-Viedma (2015), and Yu, Wang, J., Wang, J. Q., and Li (2017).

This paper presents a multi-criteria model that is able to reconcile the different points of view and criteria existing in the corporate sphere when it comes to planning the launch of new products and services from a set of previously evaluated projects (i.e., they have passed the technical, economic and financial analysis phases). The proposed model is based on the fuzzy 2-tuple linguistic model (Herrera \& Martínez, 2000a) and is aimed at managing adequately the linguistic data that express the different corporate criteria, since it allows operating with them and aggregating them without losing accuracy in the calculation of the corresponding results.

In the conception of our proposal, we have considered different aggregation processes of linguistic information that guarantee the non-loss of information, as well as the design of a mechanism that allows us to express the information in an adequate time scale to graph and adequately present the results obtained. In this way, the right moment to launch each product/service can be easily identified by the people in charge of making the corresponding decisions, thus facilitating their work.

In order to validate and better understand the model proposed, we also present its application to a practical case within the strategic planning of a telecommunications company, whose objective is to schedule the launch of a series of products/services that it wants to market. In addition, the results obtained are analysed and compared with the ones obtained by applying another model to the same case study.

The remainder of the article is structured as follows: Section 1 presents the preliminary concepts and rationale necessary for the proposal presented in this paper; Section 2 introduces the linguistic multi-criteria decision-making (LMCDM) model proposed for managing the planning of strategic goals; Section 3 illustrates the application of the model to a practical case study, analyses the results obtained and compares them with those obtained using another model; and lastly, the final section sets out the conclusions and future lines of study. In addition, Appendix 1 shows the comparison of some of the main MCDM methods for discrete problems, focused on the problem we want to solve.

\section{Material and methods}

This section is a brief introduction to the fuzzy linguistic approach, the 2-tuple linguistic model and MCDM, where the data aggregation process and the exploitation of results are carried out, since these concepts and bases will be employed throughout this paper. 


\subsection{Fuzzy linguistic approach}

Generally, in our daily work we are used to dealing with quantitative data expressed through accurate numerical values. However, many of the problems we encounter are expressed through perceptions or inaccurate knowledge, that is to say, qualitative data. A fuzzy linguistic approach can represent this type of perceptions or inaccurate knowledge using linguistic variables instead of accurate numerical values. A way of characterizing fuzzy numbers is through parametric representation of its membership functions (Bezdek, 2013).

Definition 1. Membership function: A membership function is one that pairs the elements of a discourse domain $X$ with elements of the interval [0,1], meaning that the closer $A(x)$ is to 1 , the higher the membership of $x$ to set $A$, represented in Eq. (1).

$$
A=\left\{\left(x, \mu_{A}(x)\right) ; x \in X\right\} .
$$

These membership functions can have different geometric forms of representation. In the case at hand, a uniform linear distribution was chosen, with a triangular membership function that can be represented through the Eq. (2):

$$
\mu_{A}(x)=\left\{\begin{array}{c}
0 ; \quad x<a \\
\frac{x-a}{b-a} ; a \leq x \leq b \\
\frac{c-x}{c-b} ; b \leq x \leq c \\
0 ; x>c
\end{array} .\right.
$$

Resulting from the application of the equation above, Figure 1 illustrates a uniformly distributed set of triangular functions, where each triangular function corresponds to a label $s_{i}$ and where the three points $(a, b, c)$ forming the triangle of the label $s_{2}$ are shown. A balanced set is thus obtained, with an odd number of linguistic labels, represented as $S=\left\{s_{0}, \ldots, s_{g}\right\}$.

The definition of the following properties and operators completes the semantics of the set of linguistic labels $S$ :

- Ordered set: $s_{i} \geq s_{j}$, if $i \geq j$.

- Negation operator: $\operatorname{Neg}\left(s_{i}\right)=s_{j}, j=g-i(g+1$ is the cardinality of $S)$.

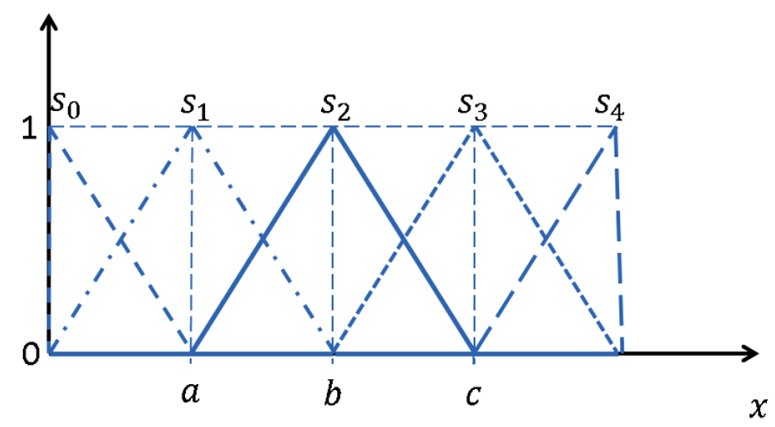

Figure 1. Example of triangular linguistic labels 
- Maximization operator: $\max \left(s_{i}, s_{j}\right)=s_{i}$, if $s_{i} \geq s_{j}$.

- Minimization operator: $\min \left(s_{i}, s_{j}\right)=s_{i}$, if $s_{i} \leq s_{j}$.

According to the above definitions and applying the extension principle (Zadeh, 1996, 1983), we have the bases required for using linguistic labels in decision-making problems.

\subsection{2-tuple linguistic model}

This model (Herrera \& Martínez, 2001, 2000a) was developed to improve accuracy in computing processes with words. It represents linguistic data through a pair of values (hence its name '2-tuple') expressed as $\left(s_{i}, \alpha\right)$, where $s_{i}$ is a linguistic term and $\alpha$ is the symbolic translation of that term. The symbolic translation of a linguistic term $s_{i} \in S=\left\{s_{0}, \ldots, s_{g}\right\}$ is a numerical value within $[-0.5,0.5)$ that represents the "difference of information" between a given value $\beta \in[0, g]$, obtained from a symbolic operation, and the index of the closest linguistic term. This linguistic model defines a couple of functions in order to translate numerical values into values expressed through a 2 -tuple representation.

The transformation of the numerical value $\beta \in[0, g]$, corresponding to the result of a symbolic aggregation operation, into the 2-tuple expressing the information equivalent to $\beta$ is obtained by applying the function $\Delta:[0, g] \rightarrow S \times[-0.5,0.5)$, defined by Eq. (3):

$$
\Delta(\beta)=\left(s_{i}, \alpha\right) \text {, with }\left\{\begin{array}{c}
s_{i}, \quad i=\operatorname{round}(\beta) \\
\alpha=\beta-i, \alpha \in[-0.5,0.5)
\end{array},\right.
$$

where round is the usual round operator which assigns the nearest integer value to $\beta$.

Please note that $\Delta$ is bijective, therefore $\Delta^{-1}: S \times[-0.5,0.5) \rightarrow[0, g]$, and it is defined as $\Delta^{-1}\left(\left(s_{i}, \alpha\right)\right)=i+\alpha$.

Therefore, based on the previous functions, the conversion of a linguistic term $s_{i}$ into a 2-tuple $\left(s_{i}, \alpha\right)$ consists in adding the zero $(0)$ value as symbolic translation, which can be represented as $\left(s_{i}, 0\right)$. This representation model is associated with a computation model allowing computing processes with words without information loss (Herrera, Alonso, Chiclana, \& Herrera-Viedma, 2009; Herrera, Herrera-Viedma, \& Martínez, 2008; Herrera \& Martínez, 2001, 2000b).

\subsection{Multi-criteria decision-making}

Papers such as the ones presented by Cabrerizo et al. (2015), Figueira, Greco, and Ehrgott (2005), Gal, Stewart, and Hanne (2013), Liou and Tzeng (2012), Liu, Dong, Chiclana, Cabrerizo, and Herrera-Viedma (2017), Pérez, Cabrerizo, and Herrera-Viedma (2010), Zavadskas, Turskis, and Kildien (2014), and Zavadskas and Turskis (2011), among others, lay out the basic principles and the progress achieved in MCDM models. The main issues in LMCDM are related to choosing the best alternative possible for a given problem from a set of alternatives $A=\left\{A_{1}, \ldots, A_{n}\right\}$ to be assessed by a set of experts $E=\left\{e_{1}, \ldots, e_{m}\right\}$, who express their assessments $x_{j}^{i}, \forall i \in\{1, \ldots, n\}, \forall j \in\{1, \ldots, m\}$ using linguistic terms from the set $S=\left\{s_{0}, \ldots, s_{g}\right\}$. The values $x_{j}^{i} \in S$ are fuzzy numbers defined by a membership function in $[0,1]$. Tong and 
Bonissone (1980) present a decision-making technique using linguistic labels with fuzzy semantics to deal with the intrinsic uncertainty of this type of problem. They also point out that decision-making results should be expressed in natural language. Authors of subsequent studies, such as Kacprzyk and Zadrozny (2001), Kacprzyk and Fedrizzi (1990), Mendel (2007a, 2007b), Li, Dong, Herrera, Herrera-Viedma, and Martínez (2017), and Martínez (2007), among others, suggest that it is not appropriate to make decisions based on numerical information when a linguistic model close to the human cognitive model has been developed.

Two phases can be distinguished in the MCDM process: information aggregation and the exploitation of results, both explained in the following subsections.

\subsubsection{Information aggregation}

Below, and following Herrera et al. (2008), several aggregation operators are defined for the 2-tuple linguistic representation, which will be used for calculating the average values of the opinions expressed by users (arithmetic mean operator) and by experts (weighted mean operator).

Definition 2. Linguistic arithmetic mean operator: Let $A=\left\{\left(r_{1}, \alpha_{1}\right), \ldots,\left(r_{n}, \alpha_{n}\right)\right\}$ be a set of linguistic 2-tuples; its arithmetic mean is calculated by means of the extended arithmetic mean operator, $\bar{x}^{e}$, defined by Eq. (4):

$$
\bar{x}^{e}\left(\left(r_{1}, \alpha_{1}\right), \ldots,\left(r_{n}, \alpha_{n}\right)\right)=\Delta\left(\frac{1}{n} \sum_{i=1}^{n} \Delta^{-1}\left(\left(r_{i}, \alpha_{i}\right)\right)\right) .
$$

Definition 3. Linguistic weighted mean operator: Let $A=\left\{\left(r_{1}, \alpha_{1}\right), \ldots,\left(r_{n}, \alpha_{n}\right)\right\}$ be a set of linguistic 2-tuples and $W=\left\{\left(w_{1}, \alpha_{1}\right), \ldots,\left(w_{n}, \alpha_{n}\right)\right\}$ a vector of 2 -tuple values corresponding to the weights of each of the 2-tuples in $A$. The extended weighted mean operator $\bar{x}_{l}^{e}$ is defined as indicated in Eq. (5):

$$
\begin{aligned}
& \bar{x}_{l}^{e}\left(\left(r_{1}, \alpha_{1}\right) \times\left(w_{1}, \alpha_{1}^{w}\right), \ldots,\left(r_{n}, \alpha_{n}\right) \times\left(w_{n}, \alpha_{n}^{w}\right)\right)= \\
& \Delta\left(\frac{\sum_{i=1}^{n} \Delta^{-1}\left(\left(r_{i}, \alpha_{i}\right)\right) \times \Delta^{-1}\left(\left(w_{i}, \alpha_{i}^{w}\right)\right)}{\sum_{i=1}^{n} \Delta^{-1}\left(\left(w_{i}, \alpha_{i}^{w}\right)\right)}\right) .
\end{aligned}
$$

\subsubsection{Exploitation of results}

The exploitation process includes the ordering of results. For the phase of ordering results, the literature provides two main groups of methods: (I) those that seek to minimize the distance to an ideal candidate, which apply techniques such as the Euclidean distance, the Manhattan distance, the Hamming distance, etc. (Kou, Lu, Peng, \& Shi, 2012), and (II) those based on maximizing the aggregate competence index, which use operators such as OWA (Ordered Weighted Averaging) and arithmetic and weighted mean variants, and which we apply in our proposal. Among the papers that develop these latter methods, it is worth citing Carlsson and Fuller (2002), Dong, Li and Herrera (2016), Dong, Zhang and Herrera-Viedma (2016), Kao and Liu (2001), Ma, Wang, J., Wang, J. Q., and Chen (2016), Yager (2007, 1994a, 1994b, 1993, 1988), and Yager and Filev (1999), among others. 


\section{Linguistic multi-criteria decision-making model proposed}

The proposed model aims at setting a schedule for the launch of a company's set of products/services $P S=\left\{P S_{1}, \ldots, P S_{n}\right\}$, that will have to be implemented in a given time span $(t)$, matching the time slot set in the company's strategic plan for the launch. Normally, this time period $(t)$ can range from 3 to 5 years, although it may vary according to the strategic plan. The launch of these products/services will be made according to the importance level of each $P S_{i}$. To establish the importance level of each $P S_{i}$, two expert groups will provide advice: the first one $\left(E^{I}\right)$ establishes the criteria to be applied and how these will be assessed, while the second one $\left(E^{I I}\right)$ establishes the weight of each criterion.

With the use of these two groups of experts we intend to introduce a separation between the establishment of the criteria to be applied and the weight that each of them will have during the assessment process, according to Pérez, Cabrerizo, Alonso, and Herrera-Viedma (2014) and $\mathrm{Xu}$ (2015). This does not mean that a given expert who belongs to one of the groups cannot be considered to be part of the other group as well. Moreover, although we could have considered establishing several hierarchical levels of importance among the experts of both groups based on their capability and experience in the decision making process, we consider that all experts have a similar level of experience in the problem addressed here, and hence the same importance in the model we propose. However, the model could be easily extended using heterogeneous decision making frameworks that exist in the literature, such as the ones proposed by Cabrerizo et al. (2013), Dong, Zhang and Herrera-Viedma (2016), and Zhang, Dong, and Herrera-Viedma (2017).

Both the criteria and their weights are expressed in natural language by means of a set of labels. The use of linguistic labels makes it easier to collect the different actors' opinions (administrators, managers, experts, technicians, etc.) under different circumstances (meetings, presentations, documents, verbal queries, etc.). At the same time, the 2-tuple representation used in the process allows the carrying out of the computing procedure with words without any information loss.

The model output is a list of different $P S_{i}$ ready for a commercial launch, structured according to the order of prioritization established for the launch of each $P S_{i}$, based on a specific set of linguistic labels represented by 2-tuples. The order is also expressed within the time slot initially established, specifying the ideal moment for the implementation of each $P S_{i}$. This ideal moment is defined by the central $(b)$ value of each label's triangular function. If a $P S_{i}$ was not launched at the ideal moment identified by the $(b)$ value of its label's triangular function, its performance would not be optimal.

Figure 2 below illustrates the different stages comprising the proposed model. The steps to be followed in each stage are detailed in the following sections.

\subsection{Inputs}

In this first stage, the following inputs required by the model are provided:

(a) Set of products/services $P S=\left\{P S_{1}, \ldots, P S_{n}\right\}$ involved in the strategic planning process. These $P S_{i}$ represent the different elements that need to be ordered chronologically for their launch within the time slot $t$. 


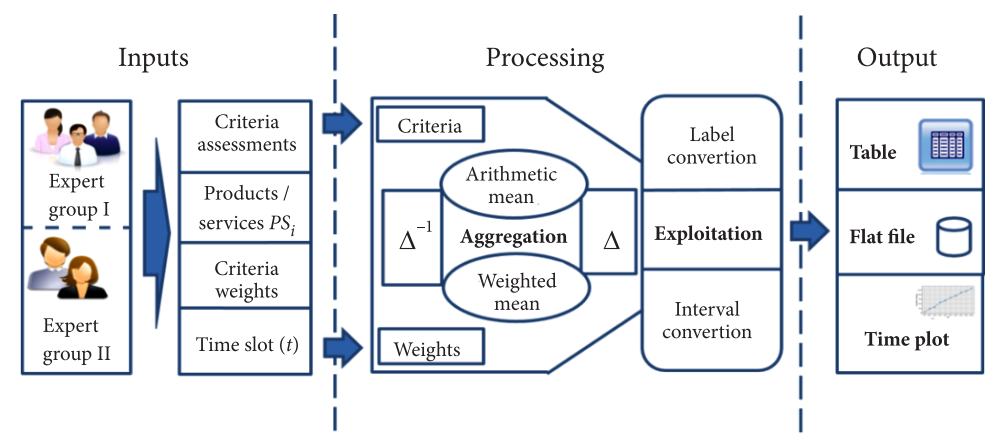

Figure 2. Diagram of the multi-criteria model proposed for scheduling the launch of products/services according to a strategic plan

(b) Set of areas involved $A=\left\{A_{1}, \ldots, A_{m}\right\}$, according to the set $P S$, as well as their corresponding assessment criteria $C_{A}=\left\{c_{11}, \ldots, c_{m p}\right\}$. It should be noted that not necessarily all the areas will have the same number of assessment criteria.

(c) Set of experts that make up the expert group I $\left(E^{I}\right)$, having the task of assessing the products/services $P S_{i}$ based on the criteria expressed by each area representative, and the expert group II $\left(E^{I I}\right)$ responsible for assigning a weight (importance level) to each criterion.

(d) Assessment of criteria $C_{A}=\left\{c_{11}, \ldots, c_{m p}\right\}$ (by the expert group $E^{I}$ ) and assignment of the corresponding weights $w_{C_{A}}=\left\{w_{11}, \ldots, w_{m p}\right\}$ (by the expert group $E^{I I}$ ).

\subsection{Processing}

The following steps need to be followed in the second stage of this model:

(a) By applying the transformation established in Section 2.2, the different data related to assessments and weights are converted in order to standardize their representation with the 2-tuple $\left(s_{i}, \alpha\right)$ format.

(b) According to Definition 2, the arithmetic mean of the individual weights assigned by the experts to the different criteria for each area are established, resulting in a single weight for each area $A_{j}$ of each $P S_{i}$ considered. For each $P S_{i}$, this is formally expressed by means of Eq. (6):

$$
\begin{gathered}
\overline{w_{C_{A_{j}}}} e\left(\left(w_{j 1}, \alpha_{j 1}^{w}\right), \ldots,\left(w_{j p}, \alpha_{j p}^{w}\right)\right)=\Delta\left(\frac{1}{p} \sum_{k=1}^{p} \Delta^{-1}\left(\left(w_{j k}, \alpha_{j k}^{w}\right)\right)\right), \\
\forall j \in\{1, \ldots, m\},
\end{gathered}
$$

where $j$ iterates on the areas concerned and $k$ iterates on the criteria of the corresponding areas.

(c) The area weights obtained in the previous step (b) are multiplied by the assessments assigned by the experts to each criterion of the corresponding area for a given $P S_{i}$. Then, the weighted mean of the resulting values of this multiplication is calculated according to Definition 3. This operation, expressed in Eq. (7) and resulting in one single value for each area $A_{j}$ involved, is repeated for each product/service $P S_{i}$ : 


$$
\bar{D}_{j}^{e}=\Delta\left(\frac{\sum_{k=1}^{p} \Delta^{-1}\left(\left(c_{j k}, \alpha_{j k}\right)\right) \times \Delta^{-1}\left(\left(w_{j}, \alpha_{j}^{w}\right)\right)}{\sum_{j=1}^{m} \Delta^{-1}\left(\left(w_{j}, \alpha_{j}^{w}\right)\right)}\right), \forall j \in\{1, \ldots, m\} .
$$

(d) New aggregation process, this time by applying the arithmetic mean of the results obtained in the previous step (c) in order to obtain one single value per $P S_{i}$ product/ service. This can be formulated as indicated in Eq. (8):

$$
\overline{P S}_{i}^{e}=\Delta\left(\frac{1}{m} \sum_{j=1}^{m} \Delta^{-1}\left(\bar{D}_{j}^{e}\right)\right), \forall i \in\{1, \ldots, n\} .
$$

(e) Given that the set of input labels indicates the importance level of the criterion assessed, and the set of output labels refers to the ideal moment for launching each product/service, we need to establish the correspondence or relation between the labels in both sets right at the end of the exploitation phase of our model. To do this, and since the products/services assessed as best by the experts (using the first set of labels) are assigned the labels to the right of that set, these will be the products/services launched first, so their labels will be located more to the left of the second set, indicating the priority level (from high to low) in the launch of the corresponding $P S_{i}$. Therefore, in order to convert one label into another, we take the complementarity principle as a basis, which can be expressed by means of Eq. (9):

$$
l_{2}=\Delta\left(1-\Delta^{-1}\left(l_{1}\right)\right)
$$

where $l_{1} \in S^{1}$ and $l_{2} \in S^{2}$ represent two labels belonging to the sets specified, which are semantically different, but are integrated by the same number of linguistic terms, with a linear and even distribution of its triangular membership function.

(f) The position of each $P S_{i}$ within the set of output labels $S^{2}$ is established for the time slot $t$, according to the needs of the case at hand (days, months, quarters, years, etc.). This calculation is made by applying Eq. (10), resulting in a numeric value belonging to the new set of labels:

$$
P\left(P S_{i}\right)=t \times \Delta^{-1}\left(\overline{P S}_{i}^{e}\right)
$$

The ordering of results is according to the order of prioritization established for each $P S_{i}$ during the launching process, using the set of output labels $\left(S^{2}\right)$. This ordering is made taking into account the 2-tuples obtained in the previous step (e).

\subsection{Output}

The following steps are to be taken in this final phase of our model:

(a) Preparation of the final results table showing the values represented by 2-tuples (using labels from the set $S^{2}$ ) for each $P S_{i}$, as well as the ideal moment for their launching.

(b) Generation of a flat file (in CSV format) containing all the information of the model obtained, which may serve both as a historical record of the case and as a basis for later analyses of the case, possibly with different tools. 
(c) Graphic representation of the ideal moment for launching each $P S_{i}$ within the time slot $t$, based on the prioritization established by the model for each product/service.

The model presented above has been implemented with IBM Co.s SPSS Modeler (IBM, n. d.) software, as shown in Figure 3.

As an application example of the different steps in the above-described process, a real case study from the ICT sector is presented below.

\section{Case study}

To illustrate the application of the model proposed in this paper, this section presents a case study based on a strategic planning process from the ICT sector in Ecuador. The case study is described below, with explanations of the model application, followed by an analysis and interpretation of the results obtained, as well as a comparative and sensitivity analysis.

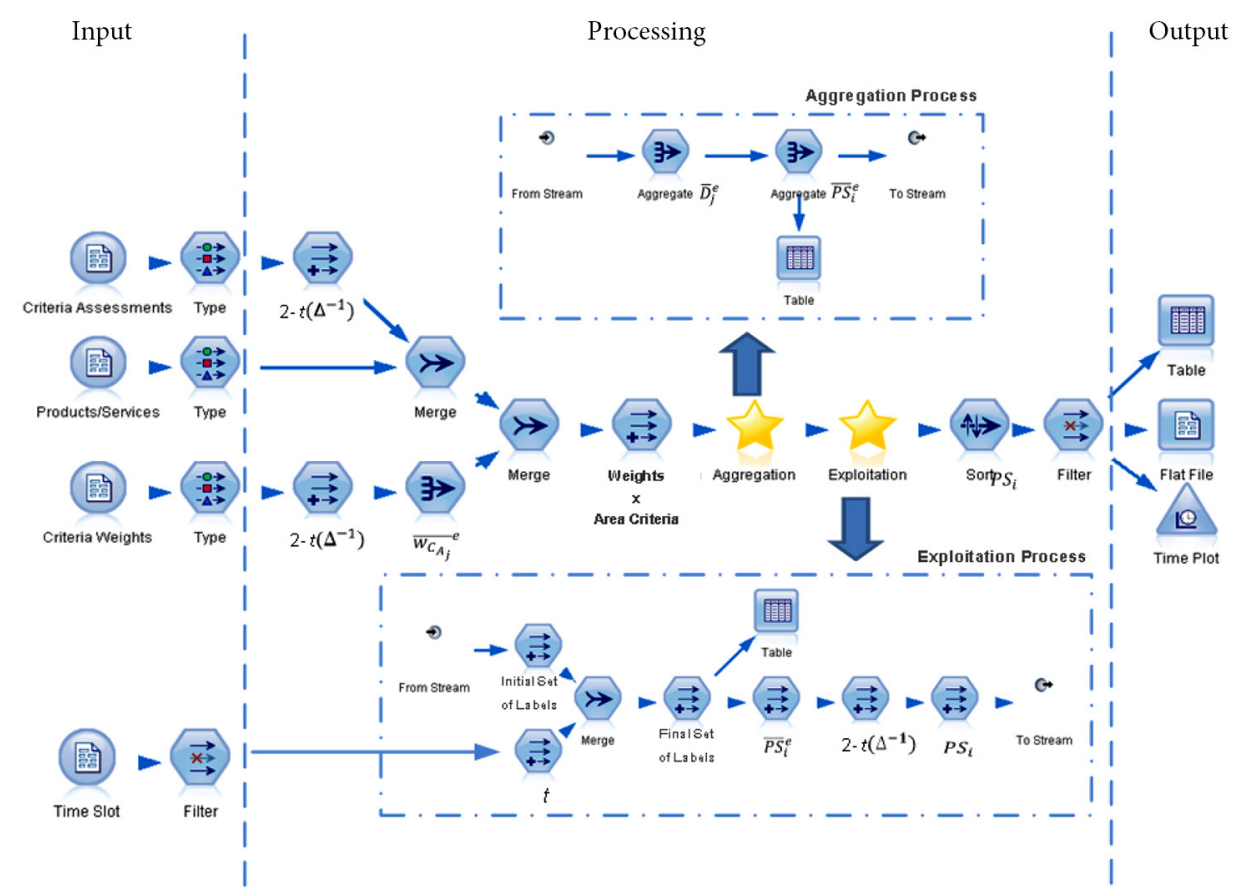

Figure 3. Implementation of the LMCDM model proposed using IBM SPSS Modeler

\subsection{Description of the case study selected and application of the proposed model}

The case study selected is related to the scheduling of the launch of different products/services by a telecommunications company, based on the prioritization established for these products/services and according to the goals identified in the company's strategic planning. This example consists of a set of products/services $\left(P S_{i}\right)$ to be launched on the market at different points within the time frame $(t)$ established in the strategic planning, namely four 
years. Therefore, the launch of each product/service may be considered as a project of the company. The proposed model was applied to the assessment of the importance of each project $P S_{i}$ and to establish an implementation schedule based on the opinions (criteria) and importance levels (weights) expressed by the different groups of experts. In order to express both the assessments and the weights assigned to the criteria, we established the set $S^{1}$, integrated by the following five linguistic labels: $s_{0}^{1}=$ Not important at all (NI), $s_{1}^{1}=$ Less important (LI), $s_{2}^{1}=\operatorname{Neutral}(\mathrm{N}), s_{3}^{1}=\operatorname{Important}(\mathrm{I})$, and $s_{4}^{1}=\operatorname{Very} \operatorname{Important}(\mathrm{VI})$.

In this particular case, we have a set of 10 different projects (products/services) $P S=\left\{P S_{1}, \ldots, P S_{10}\right\}$ to be implemented along the 4 year time slot $(t)$ defined in the strategic planning or, in other words, 1460 days. The implementation time frame was divided into five evenly distributed labels, which integrate the set $S^{2}$, the semantics of which denote the immediacy of each product $P S_{i}$ launch. The labels forming this second set are: $s_{0}^{2}=$ Immediate (IM), $s_{1}^{2}=$ Short Term (ST), $s_{2}^{2}=\operatorname{Medium~Term~(MT),~} s_{3}^{2}=$ Long Term (LT), and $s_{4}^{2}=$ Very Long Term (VLT). These labels are used in the final phase of the model to establish the order of prioritization (in the development or implementation phase), based on the importance levels (expressed in terms of immediacy) assigned to each $P S_{i}$.

The participating experts defined five assessment criteria for each of the areas concerned (Legal, Technical, Sales and Financial), so that each area has its own criteria that are different from the rest of the areas. Table 1 shows the assessments assigned by the expert group $E^{I}$ to every project $P S_{i}$, for which they had to assess the criteria established in every area concerned.

Table 1. Assessments expressed by the expert group I $\left(E^{I}\right)$ for every $P S_{i}$ proposed

\begin{tabular}{|c|c|c|c|c|c|}
\hline$P S_{1}$ & $c_{1}$ & $c_{2}$ & $c_{3}$ & $c_{4}$ & $c_{5}$ \\
\hline Legal & $\mathrm{I}$ & $\mathrm{N}$ & $\mathrm{N}$ & $\mathrm{VI}$ & $\mathrm{VI}$ \\
\hline Technical & $\mathrm{VI}$ & $\mathrm{VI}$ & $\mathrm{VI}$ & $\mathrm{VI}$ & $\mathrm{VI}$ \\
\hline Sales & $\mathrm{VI}$ & $\mathrm{VI}$ & $\mathrm{VI}$ & $\mathrm{VI}$ & $\mathrm{VI}$ \\
\hline Financial & $\mathrm{VI}$ & $\mathrm{VI}$ & $\mathrm{VI}$ & $\mathrm{VI}$ & $\mathrm{VI}$ \\
\hline
\end{tabular}

\begin{tabular}{|c|c|c|c|c|c|}
\hline$P S_{2}$ & $c_{1}$ & $c_{2}$ & $c_{3}$ & $c_{4}$ & $c_{5}$ \\
\hline Legal & VI & VI & VI & VI & VI \\
\hline Technical & VI & VI & VI & VI & VI \\
\hline Sales & VI & VI & VI & VI & VI \\
\hline Financial & VI & VI & VI & VI & VI \\
\hline
\end{tabular}

\begin{tabular}{|c|c|c|c|c|c|}
\hline$P S_{3}$ & $c_{1}$ & $c_{2}$ & $c_{3}$ & $c_{4}$ & $c_{5}$ \\
\hline Legal & $\mathrm{I}$ & $\mathrm{I}$ & $\mathrm{I}$ & $\mathrm{I}$ & $\mathrm{I}$ \\
\hline Technical & $\mathrm{I}$ & $\mathrm{I}$ & $\mathrm{N}$ & $\mathrm{N}$ & $\mathrm{N}$ \\
\hline Sales & $\mathrm{N}$ & $\mathrm{N}$ & $\mathrm{VI}$ & $\mathrm{VI}$ & $\mathrm{VI}$ \\
\hline Financial & $\mathrm{VI}$ & $\mathrm{VI}$ & $\mathrm{VI}$ & $\mathrm{VI}$ & $\mathrm{VI}$ \\
\hline
\end{tabular}

\begin{tabular}{|c|c|c|c|c|c|}
\hline $\mathrm{PS}_{4}$ & $c_{1}$ & $c_{2}$ & $c_{3}$ & $c_{4}$ & $c_{5}$ \\
\hline Legal & $\mathrm{I}$ & $\mathrm{I}$ & $\mathrm{I}$ & $\mathrm{LI}$ & $\mathrm{LI}$ \\
\hline Technical & $\mathrm{LI}$ & $\mathrm{LI}$ & $\mathrm{LI}$ & $\mathrm{LI}$ & $\mathrm{LI}$ \\
\hline Sales & $\mathrm{LI}$ & $\mathrm{N}$ & $\mathrm{N}$ & $\mathrm{N}$ & $\mathrm{N}$ \\
\hline Financial & $\mathrm{N}$ & $\mathrm{NI}$ & $\mathrm{NI}$ & $\mathrm{NI}$ & $\mathrm{VI}$ \\
\hline
\end{tabular}

\begin{tabular}{|c|c|c|c|c|c|}
\hline$P S_{5}$ & $c_{1}$ & $c_{2}$ & $c_{3}$ & $c_{4}$ & $c_{5}$ \\
\hline Legal & I & I & I & I & I \\
\hline Technical & LI & LI & LI & LI & LI \\
\hline Sales & N & NI & NI & VI & VI \\
\hline Financial & VI & VI & VI & VI & VI \\
\hline
\end{tabular}

\begin{tabular}{|c|c|c|c|c|c|}
\hline$P_{6}$ & $c_{1}$ & $c_{2}$ & $c_{3}$ & $c_{4}$ & $c_{5}$ \\
\hline Legal & $\mathrm{VI}$ & $\mathrm{VI}$ & $\mathrm{VI}$ & $\mathrm{VI}$ & $\mathrm{VI}$ \\
\hline Technical & $\mathrm{VI}$ & $\mathrm{VI}$ & $\mathrm{VI}$ & $\mathrm{VI}$ & $\mathrm{VI}$ \\
\hline Sales & $\mathrm{VI}$ & $\mathrm{VI}$ & $\mathrm{VI}$ & $\mathrm{VI}$ & $\mathrm{VI}$ \\
\hline Financial & $\mathrm{VI}$ & $\mathrm{VI}$ & $\mathrm{VI}$ & $\mathrm{VI}$ & $\mathrm{VI}$ \\
\hline
\end{tabular}


End of Table 1

\begin{tabular}{|c|c|c|c|c|c|}
\hline$P S_{7}$ & $c_{1}$ & $c_{2}$ & $c_{3}$ & $c_{4}$ & $c_{5}$ \\
\hline Legal & $\mathrm{I}$ & $\mathrm{LI}$ & $\mathrm{NI}$ & $\mathrm{NI}$ & $\mathrm{NI}$ \\
\hline Technical & $\mathrm{NI}$ & $\mathrm{NI}$ & $\mathrm{VI}$ & $\mathrm{VI}$ & $\mathrm{VI}$ \\
\hline Sales & $\mathrm{VI}$ & $\mathrm{VI}$ & $\mathrm{VI}$ & $\mathrm{VI}$ & $\mathrm{VI}$ \\
\hline Financial & $\mathrm{VI}$ & $\mathrm{VI}$ & $\mathrm{VI}$ & $\mathrm{VI}$ & $\mathrm{VI}$ \\
\hline
\end{tabular}

\begin{tabular}{|c|c|c|c|c|c|}
\hline$P S_{8}$ & $c_{1}$ & $c_{2}$ & $c_{3}$ & $c_{4}$ & $c_{5}$ \\
\hline Legal & $\mathrm{I}$ & $\mathrm{I}$ & $\mathrm{I}$ & $\mathrm{I}$ & $\mathrm{LI}$ \\
\hline Technical & $\mathrm{N}$ & $\mathrm{N}$ & $\mathrm{N}$ & $\mathrm{N}$ & $\mathrm{N}$ \\
\hline Sales & $\mathrm{N}$ & $\mathrm{N}$ & $\mathrm{NI}$ & $\mathrm{NI}$ & $\mathrm{NI}$ \\
\hline Financial & $\mathrm{NI}$ & $\mathrm{NI}$ & $\mathrm{VI}$ & $\mathrm{VI}$ & $\mathrm{VI}$ \\
\hline
\end{tabular}

\begin{tabular}{|c|c|c|c|c|c|}
\hline$P S_{9}$ & $c_{1}$ & $c_{2}$ & $c_{3}$ & $c_{4}$ & $c_{5}$ \\
\hline Legal & $\mathrm{I}$ & $\mathrm{I}$ & $\mathrm{LI}$ & $\mathrm{N}$ & $\mathrm{N}$ \\
\hline Technical & $\mathrm{N}$ & $\mathrm{N}$ & $\mathrm{N}$ & $\mathrm{N}$ & $\mathrm{N}$ \\
\hline Sales & $\mathrm{N}$ & $\mathrm{N}$ & $\mathrm{VI}$ & $\mathrm{VI}$ & $\mathrm{VI}$ \\
\hline Financial & $\mathrm{VI}$ & $\mathrm{VI}$ & $\mathrm{VI}$ & $\mathrm{VI}$ & $\mathrm{VI}$ \\
\hline
\end{tabular}

\begin{tabular}{|c|c|c|c|c|c|}
\hline$P S_{10}$ & $c_{1}$ & $c_{2}$ & $c_{3}$ & $c_{4}$ & $c_{5}$ \\
\hline Legal & $\mathrm{I}$ & $\mathrm{I}$ & $\mathrm{I}$ & $\mathrm{I}$ & $\mathrm{LI}$ \\
\hline Technical & $\mathrm{LI}$ & $\mathrm{N}$ & $\mathrm{N}$ & $\mathrm{N}$ & $\mathrm{NI}$ \\
\hline Sales & $\mathrm{NI}$ & $\mathrm{NI}$ & $\mathrm{NI}$ & $\mathrm{NI}$ & $\mathrm{NI}$ \\
\hline Financial & $\mathrm{NI}$ & $\mathrm{NI}$ & $\mathrm{VI}$ & $\mathrm{VI}$ & $\mathrm{VI}$ \\
\hline
\end{tabular}

Likewise, Table 2 shows the weights assigned by the expert group $E^{I I}$ to each project $P S_{i}$, indicating the importance levels assigned to every criterion identified in each area.

Table 2. Weights or importance levels assigned by the expert group II $\left(E^{I I}\right)$ to each criterion identified in the areas concerned, for each $P S_{i}$ proposed

\begin{tabular}{|c|c|c|c|c|c|}
\hline$P S_{1}$ & $w c_{1}$ & $w c_{2}$ & $w c_{3}$ & $w c_{4}$ & $w c_{5}$ \\
\hline Legal & VI & I & VI & I & VI \\
\hline Technical & I & I & I & VI & VI \\
\hline Sales & I & VI & I & I & VI \\
\hline Financial & I & I & N & VI & VI \\
\hline
\end{tabular}

\begin{tabular}{|c|c|c|c|c|c|}
\hline$P S_{2}$ & $w c_{1}$ & $w c_{2}$ & $w c_{3}$ & $w c_{4}$ & $w c_{5}$ \\
\hline Legal & VI & VI & VI & VI & VI \\
\hline Technical & VI & VI & VI & VI & VI \\
\hline Sales & VI & VI & VI & VI & VI \\
\hline Financial & I & I & VI & VI & VI \\
\hline
\end{tabular}

\begin{tabular}{|c|c|c|c|c|c|}
\hline$P S_{3}$ & $w c_{1}$ & $w c_{2}$ & $w c_{3}$ & $w c_{4}$ & $w c_{5}$ \\
\hline Legal & $\mathrm{I}$ & $\mathrm{I}$ & $\mathrm{N}$ & $\mathrm{VI}$ & $\mathrm{VI}$ \\
\hline Technical & $\mathrm{I}$ & $\mathrm{I}$ & $\mathrm{I}$ & $\mathrm{VI}$ & $\mathrm{VI}$ \\
\hline Sales & $\mathrm{I}$ & $\mathrm{VI}$ & $\mathrm{VI}$ & $\mathrm{VI}$ & $\mathrm{VI}$ \\
\hline Financial & $\mathrm{I}$ & $\mathrm{I}$ & $\mathrm{N}$ & $\mathrm{N}$ & $\mathrm{NI}$ \\
\hline
\end{tabular}

\begin{tabular}{|c|c|c|c|c|c|}
\hline$P_{4}$ & $w c_{1}$ & $w c_{2}$ & $w c_{3}$ & $w c_{4}$ & $w c_{5}$ \\
\hline Legal & LI & LI & N & NI & NI \\
\hline Technical & LI & N & NI & NI & NI \\
\hline Sales & LI & LI & LI & LI & N \\
\hline Financial & LI & N & NI & NI & NI \\
\hline
\end{tabular}

\begin{tabular}{|c|c|c|c|c|c|}
\hline$P S_{5}$ & $w c_{1}$ & $w c_{2}$ & $w c_{3}$ & $w c_{4}$ & $w c_{5}$ \\
\hline Legal & $\mathrm{I}$ & $\mathrm{I}$ & $\mathrm{N}$ & $\mathrm{N}$ & $\mathrm{N}$ \\
\hline Technical & $\mathrm{I}$ & $\mathrm{I}$ & $\mathrm{I}$ & $\mathrm{VI}$ & $\mathrm{VI}$ \\
\hline Sales & $\mathrm{I}$ & $\mathrm{I}$ & $\mathrm{LI}$ & $\mathrm{LI}$ & $\mathrm{N}$ \\
\hline Financial & $\mathrm{I}$ & $\mathrm{I}$ & $\mathrm{LI}$ & $\mathrm{N}$ & $\mathrm{N}$ \\
\hline
\end{tabular}

\begin{tabular}{|c|c|c|c|c|c|}
\hline$P S_{6}$ & $w c_{1}$ & $w c_{2}$ & $w c_{3}$ & $w c_{4}$ & $w c_{5}$ \\
\hline Legal & $\mathrm{I}$ & $\mathrm{N}$ & $\mathrm{VI}$ & $\mathrm{I}$ & $\mathrm{VI}$ \\
\hline Technical & $\mathrm{I}$ & $\mathrm{I}$ & $\mathrm{N}$ & $\mathrm{VI}$ & $\mathrm{VI}$ \\
\hline Sales & $\mathrm{I}$ & $\mathrm{VI}$ & $\mathrm{VI}$ & $\mathrm{VI}$ & $\mathrm{VI}$ \\
\hline Financial & $\mathrm{I}$ & $\mathrm{N}$ & $\mathrm{N}$ & $\mathrm{VI}$ & $\mathrm{VI}$ \\
\hline
\end{tabular}

\begin{tabular}{|c|c|c|c|c|c|}
\hline$P S_{7}$ & $w c_{1}$ & $w c_{2}$ & $w c_{3}$ & $w c_{4}$ & $w c_{5}$ \\
\hline Legal & $\mathrm{I}$ & $\mathrm{LI}$ & $\mathrm{N}$ & $\mathrm{N}$ & $\mathrm{N}$ \\
\hline Technical & $\mathrm{I}$ & $\mathrm{I}$ & $\mathrm{I}$ & $\mathrm{I}$ & $\mathrm{VI}$ \\
\hline Sales & $\mathrm{I}$ & $\mathrm{I}$ & $\mathrm{LI}$ & $\mathrm{N}$ & $\mathrm{NI}$ \\
\hline Financial & $\mathrm{I}$ & $\mathrm{I}$ & $\mathrm{N}$ & $\mathrm{N}$ & $\mathrm{VI}$ \\
\hline
\end{tabular}

\begin{tabular}{|c|c|c|c|c|c|}
\hline$P S_{8}$ & $w c_{1}$ & $w c_{2}$ & $w c_{3}$ & $w c_{4}$ & $w c_{5}$ \\
\hline Legal & LI & LI & $\mathrm{N}$ & $\mathrm{NI}$ & $\mathrm{N}$ \\
\hline Technical & $\mathrm{I}$ & $\mathrm{I}$ & $\mathrm{LI}$ & $\mathrm{N}$ & $\mathrm{NI}$ \\
\hline Sales & $\mathrm{I}$ & $\mathrm{N}$ & $\mathrm{LI}$ & $\mathrm{LI}$ & $\mathrm{N}$ \\
\hline Financial & $\mathrm{LI}$ & $\mathrm{I}$ & $\mathrm{LI}$ & $\mathrm{N}$ & $\mathrm{N}$ \\
\hline
\end{tabular}


End of Table 2

\begin{tabular}{|c|c|c|c|c|c|}
\hline$P S_{9}$ & $w c_{1}$ & $w c_{2}$ & $w c_{3}$ & $w c_{4}$ & $w c_{5}$ \\
\hline Legal & $\mathrm{I}$ & $\mathrm{I}$ & $\mathrm{N}$ & $\mathrm{N}$ & $\mathrm{VI}$ \\
\hline Technical & $\mathrm{I}$ & $\mathrm{I}$ & $\mathrm{I}$ & $\mathrm{N}$ & $\mathrm{VI}$ \\
\hline Sales & $\mathrm{I}$ & $\mathrm{N}$ & $\mathrm{VI}$ & $\mathrm{VI}$ & $\mathrm{VI}$ \\
\hline Financial & $\mathrm{I}$ & $\mathrm{N}$ & $\mathrm{N}$ & $\mathrm{VI}$ & $\mathrm{VI}$ \\
\hline
\end{tabular}

\begin{tabular}{|c|c|c|c|c|c|}
\hline$P S_{10}$ & $w c_{1}$ & $w c_{2}$ & $w c_{3}$ & $w c_{4}$ & $w c_{5}$ \\
\hline Legal & $\mathrm{I}$ & $\mathrm{LI}$ & $\mathrm{N}$ & $\mathrm{I}$ & $\mathrm{N}$ \\
\hline Technical & $\mathrm{N}$ & $\mathrm{N}$ & $\mathrm{N}$ & $\mathrm{LI}$ & $\mathrm{VI}$ \\
\hline Sales & $\mathrm{I}$ & $\mathrm{LI}$ & $\mathrm{LI}$ & $\mathrm{N}$ & $\mathrm{I}$ \\
\hline Financial & $\mathrm{N}$ & $\mathrm{I}$ & $\mathrm{I}$ & $\mathrm{I}$ & $\mathrm{N}$ \\
\hline
\end{tabular}

In order for all the necessary operations to be carried out with no information loss, the linguistic labels need to be expressed through the 2 -tuple representation, i.e. $\left(s_{i}, \alpha\right)$. Using this representation and applying the step (b) in Section 2.2, Table 3 shows the result of the aggregation of the different weights assigned to the criteria in each area, thus generating one single weight per area for each project $P S_{i}$. As an example of this aggregation process, the calculation made to obtain the aggregated weight corresponding to the Legal area for $P S_{1}$, denoted as $\overline{w_{L}}\left(P S_{1}\right)$, is shown below:

$$
\begin{aligned}
& \overline{w_{L}}\left(P S_{1}\right)=\Delta\left(\frac{1}{5} \sum \Delta^{-1}((V I,+0000) ;(I,+0000) ;(V I,+0000) ;(I,+0000) ;(V I,+0000))\right)= \\
& \Delta\left(\frac{1}{5} \sum(1 ; 0.750 ; 1 ; 0.750 ; 1)\right)=(V I,-0.100) .
\end{aligned}
$$

Table 3. Resulting weights per area for each product/service concerned

\begin{tabular}{|l|l|}
\hline$P S_{1}$ & Weight \\
\hline Legal & $(\mathrm{VI},-0.100)$ \\
\hline Technical & $(\mathrm{I},+0.100)$ \\
\hline Sales & $(\mathrm{I},+0.100)$ \\
\hline Financial & $(\mathrm{I},+0.050)$ \\
\hline
\end{tabular}

\begin{tabular}{|l|l|}
\hline $\mathrm{PS}_{2}$ & Weight \\
\hline Legal & $(\mathrm{VI},-0.000)$ \\
\hline Technical & $(\mathrm{VI},-0.000)$ \\
\hline Sales & $(\mathrm{VI},-0.000)$ \\
\hline Financial & $(\mathrm{VI},-0.100)$ \\
\hline
\end{tabular}

\begin{tabular}{|l|l|}
\hline $\mathrm{PS}_{3}$ & Weight \\
\hline Legal & $(\mathrm{I},+0.050)$ \\
\hline Technical & $(\mathrm{I},+0.100)$ \\
\hline Sales & $(\mathrm{VI},-0.050)$ \\
\hline Financial & $(\mathrm{N},+0.000)$ \\
\hline
\end{tabular}

\begin{tabular}{|l|l|}
\hline$P S_{4}$ & Weight \\
\hline Legal & $(\mathrm{LI},-0.050)$ \\
\hline Technical & $(\mathrm{LI},-0.100)$ \\
\hline Sales & $(\mathrm{LI},+0.050)$ \\
\hline Financial & $(\mathrm{LI},-0.100)$ \\
\hline
\end{tabular}

\begin{tabular}{|l|l|}
\hline$P S_{5}$ & Weight \\
\hline Legal & $(\mathrm{N},+0.100)$ \\
\hline Technical & $(\mathrm{I},+0.100)$ \\
\hline Sales & $(\mathrm{N},+0.000)$ \\
\hline Financial & $(\mathrm{N},+0.050)$ \\
\hline
\end{tabular}

\begin{tabular}{|l|l|}
\hline$P S_{6}$ & Weight \\
\hline Legal & $(\mathrm{I},+0.100)$ \\
\hline Technical & $(\mathrm{I},+0.050)$ \\
\hline Sales & $(\mathrm{VI},-0.050)$ \\
\hline Financial & $(\mathrm{I},+0.000)$ \\
\hline
\end{tabular}

\begin{tabular}{|l|l|}
\hline$P S_{7}$ & Weight \\
\hline Legal & $(\mathrm{N},+0.000)$ \\
\hline Technical & $(\mathrm{I},+0.050)$ \\
\hline Sales & $(\mathrm{N},-0.050)$ \\
\hline Financial & $(\mathrm{I},-0.050)$ \\
\hline
\end{tabular}

\begin{tabular}{|l|l|}
\hline$P S_{8}$ & Weight \\
\hline Legal & $(\mathrm{LI},+0.050)$ \\
\hline Technical & $(\mathrm{N},-0.050)$ \\
\hline Sales & $(\mathrm{N},-0.050)$ \\
\hline Financial & $(\mathrm{N},-0.050)$ \\
\hline
\end{tabular}

\begin{tabular}{|l|l|}
\hline$P S_{9}$ & Weight \\
\hline Legal & $(\mathrm{I},-0.050)$ \\
\hline Technical & $(\mathrm{I},+0.000)$ \\
\hline Sales & $(\mathrm{I},+0.100)$ \\
\hline Financial & $(\mathrm{I},+0.000)$ \\
\hline
\end{tabular}

\begin{tabular}{|l|l|}
\hline$P S_{10}$ & Weight \\
\hline Legal & $(\mathrm{N},+0.050)$ \\
\hline Technical & $(\mathrm{N},+0.050)$ \\
\hline Sales & $(\mathrm{N},+0.000)$ \\
\hline Financial & $(\mathrm{I},-0.100)$ \\
\hline
\end{tabular}


Once the single weights per area are obtained for each project (i.e. product/service) considered, we carry out the operations corresponding to steps (c) and (d) of the processing stage, as explained in Section 2.2. Finally, the results obtained are shown in Figure 4. In order for the reader to better understand how the values shown in this figure are obtained, we present below how the value corresponding to $P S_{1}$ is calculated by applying the two mentioned steps of our model:

$$
\begin{gathered}
\Delta \overline{D_{L}}\left(P S_{1}\right)= \\
\Delta\left(\frac{\sum \Delta^{-1}\left(w_{L}\left(P S_{1}\right) \times((I,+0.000) ;(N,+0.0000) ;(N,+0.0000) ;(V I,+0.000) ;(V I,+0.000))\right.}{5}\right)= \\
\Delta\left(\frac{(0.675 ; 0.450 ; 0.450 ; 0.900 ; 0.900)}{5}\right)=(I,-0.075) \\
\overline{P S_{1}}=\Delta\left(\frac{1}{4} \sum \Delta^{-1}\left(\overline{D_{L}}\left(P S_{1}\right) ; \overline{D_{T}}\left(P S_{1}\right) ; \overline{D_{S}}\left(P S_{1}\right) ; \overline{D_{F}}\left(P S_{1}\right)\right)\right)= \\
\Delta\left(\frac{1}{4} \sum \Delta^{-1}((I,-0.075) ;(I,+0.100) ;(I,+0.100) ;(I,+0.050))\right)= \\
\Delta\left(\frac{1}{4} \sum(0.675 ; 0.850 ; 0.850 ; 0.800)\right)=(I,+0.0438) .
\end{gathered}
$$

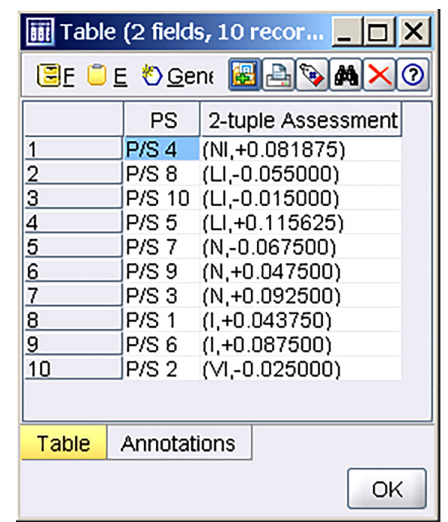

Figure 4. Final assessments ordered by

importance level of the input labels

The assessment labels (2-tuple values) obtained for each product/service displayed in Figure 4 are ordered from lower to higher (according to the input set $S^{1}=\{\mathrm{NI}, \ldots, \mathrm{VI}\}$ ). However, to convert these labels to the new set of output labels $S^{2}=\{\mathrm{IM}, \ldots, \mathrm{VLT}\}-$ following the steps (e) and (f) of the procedure described in Section 2.2 - we need to order them from higher to lower in terms of immediacy, that is, the products/services that are supposed to be launched first would occupy the first positions, as illustrated in Figure 5. Again, we present as an example the calculation made to obtain the value corresponding to $P S_{1}$ :

Label conversion: $l_{1} \in S^{1} \rightarrow l_{2} \in S^{2}$, by applying $l_{2}=\Delta\left(1-\Delta^{-1}\left(l_{1}\right)\right)$, 


$$
\begin{gathered}
l_{2}\left(P S_{1}\right)=\Delta\left(1-\Delta^{-1}\left(l_{1}\left(P S_{1}\right)\right)=\Delta\left(1-\Delta^{-1}((I,+0.0438))\right)=\Delta(1-0.793)=(S T,-0.0438),\right. \\
P\left(P S_{1}\right)=t \times \Delta^{-1}\left(l_{2}\left(P S_{1}\right)\right)=1460 \times \Delta^{-1}((S T,-0.0438))=301 .
\end{gathered}
$$

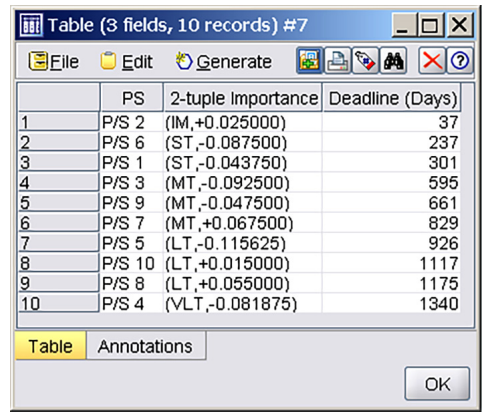

Figure 5. Final results sorted and expressed using the final set of labels

This is to be interpreted as follows: the assessments with greatest importance level correspond to the projects to be implemented with the greatest immediacy. In other words, the importance level is directly proportional to the launch priority established for the product/ service $P S_{i}$ concerned. This prioritization is represented on the time line ( $x$ axis) in Figure 6 , for a four-year period, i.e. 1460 days, in such a way that the best valued projects are the first ones that will be launched, and therefore they are depicted more to the left in the figure. Moreover, the $y$ (ordinate) axis in Figure 6 represents the degree of membership to the triangular function that characterizes the corresponding fuzzy number, being this value included in the interval $[0,1]$, as indicated in Definition 1 . Thus, the value obtained as the ideal moment for the launch of each alternative corresponds to the central value $(b)$ of the corresponding triangular function (see Figure 1), which is when the function reaches its maximum membership value. A total of 15 triangular functions are represented in Figure 6.

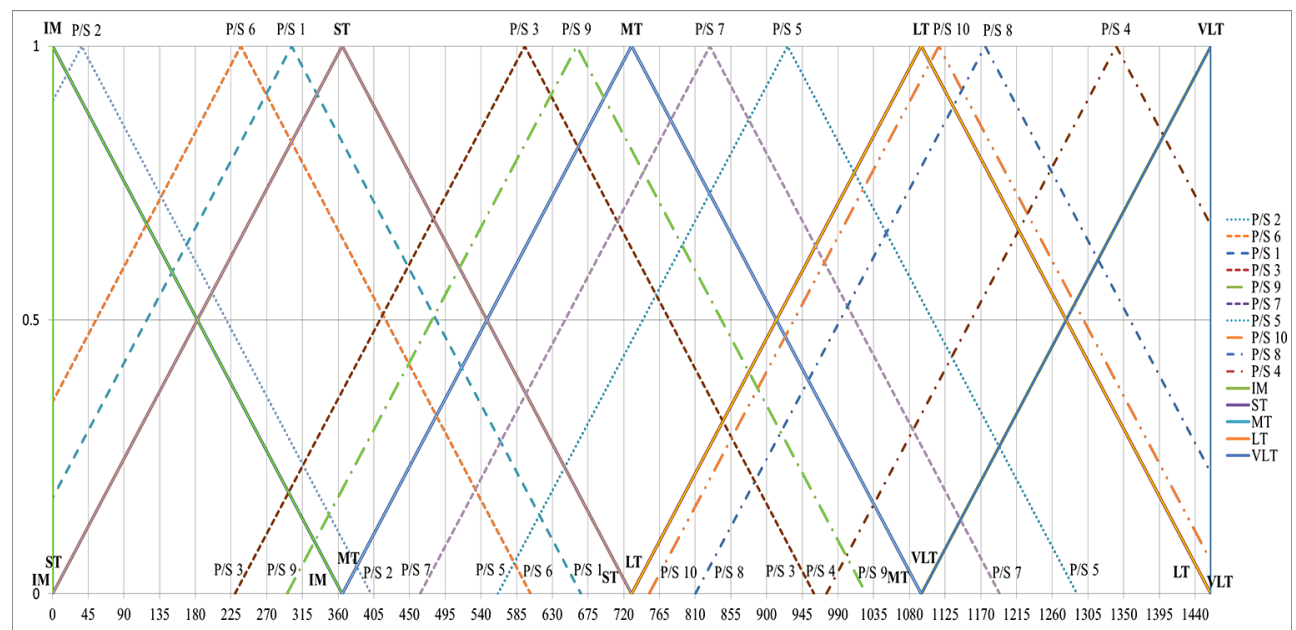

Figure 6. Graphical representation of the launch of products/services according to the strategic plan 
The ones with solid line represent the five labels belonging to the output set $S^{2}=\{\mathrm{IM}, \mathrm{ST}$, MT, LT, VLT\}, while the remainder, depicted with dashed line, correspond to each of the 10 alternatives or projects (i.e. the $P S_{i}$ products/services) considered. Each of these 15 values are represented in Figure 6 in two ways: (1) the triangular function already indicated, which represents the corresponding 2-tuple using the set of output labels $S^{2}$; and (2) the projection of the central vertex of the triangular membership function on the $x$ axis indicates the specific day (within the four-year period) which is equivalent to the corresponding 2-tuple, and therefore the ideal day on which the launch should be made, according to the assessment carried out by the experts.

\subsection{Analysis of results}

As an example, we can see that, according to the assessments expressed by the experts for the product/service $P_{3}$ (expressed as P/S 3 in Figure 4, Figure 5 and Figure 6), the ideal moment for its launch is day 595 of the strategic planning (see Figure 5). The assessment obtained by this element is Neutral $(\mathrm{N},+0.092500)$, according to the input labels (see Figure 4), while, according to the output labels, its implementation should be done at the Medium Term (MT,-0.092500), as shown in Figure 5. Since the results are represented with a triangular membership function (see Figure 6), a variation in the time of the launch would impact the appropriateness of that launch, represented in the diagram below on the $y$-axis (membership value). Thus, the maximum membership (value =1) for $P S_{3}$ is day 595, i.e. this is the ideal moment for this product/service to be launched. Nonetheless, this does not mean that a previous or subsequent launch to this calculated ideal day is not adequate. In fact, there could be other variables not taken into account in the assessments given by the experts that justify a launch in practice outside the ideal moment established by our model.

Therefore, the final results ordered and expressed according to the final set of linguistic labels $S^{2}$ are those displayed in Figure 5 and graphically illustrated in Figure 6 . The $x$-axis of this graph represents the time scale established for this case study (4 years or 1460 days), providing additional information on the time frame and expressed in calendar days. This information is also illustrated in Figure 5 in the Deadline (Days) column.

The analysis of the results obtained shows that, based on the initial assessments provided by the expert group I $\left(E^{I}\right)$ and the weights assigned by the expert group II $\left(E^{I I}\right)$, and by applying the LMCDM model proposed, we obtain a clear planning of the timing (within the time frame $t$ ) of the launch for all the different products/services $P S_{i}$ considered in the company's strategic plan. Besides, the graph depicted in Figure 6 shows both the order and the ideal moment of launch for each $P S_{i}$ addressed in the strategic development plan of the company. This example illustrates how the model is able to convert the experts' assessments into a time scale easily understandable by anyone, by expressing the results through a set of linguistic labels closer to the specific language employed in this type of task.

Figure 7 illustrates a different way of displaying results, by expressing them directly with the $P S_{i}$ concerned on the $x$-axis. It shows the continuity in time of the implementation of the different $P S_{i}$ projects, i.e. the launch sequence for the products/services concerned in this particular case. In the event of any parallel launch of projects (simultaneously), these products/services would be deployed with the same value on the $y$-axis. 


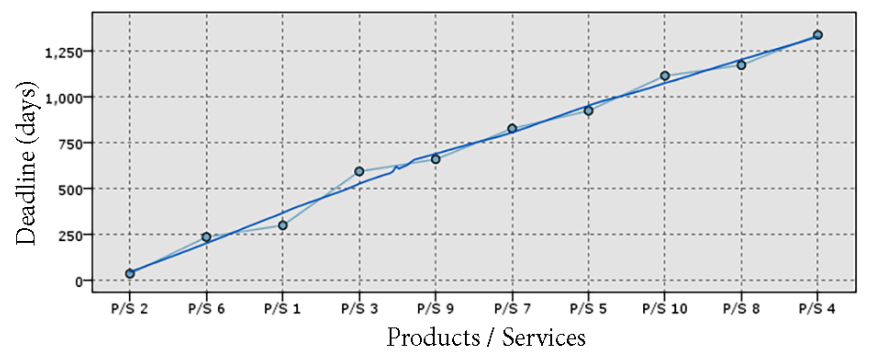

Figure 7. Order of launch of each project $P S_{i}$ according to its importance level

\subsection{Comparative and sensitivity analysis}

In order to present the main advantages of the solution presented with respect to other methods for expressing results, this section will compare and analyse the results obtained with our model for the case study that was explained in Section 3.1, with the aim of showing the following two aspects:

a) Discrimination degree of the model between the different alternatives considered.

b) Sensitivity analysis of the model to the variation of the weights introduced.

\section{a) Discrimination degree of the model}

According to Howard (1991), we have studied the discrimination degree of the different alternatives considered when using our model, as well as comparing the results obtained with the ones obtained with another model. In fact, Table 4 shows the results of this comparative study, where the second column presents the outcomes expressed in a purely linguistic model (with loss of information) and the third column shows the ones obtained with the linguistic 2-tuple model (without loss of information) that we have proposed.

Table 4. Results obtained for the case study presented, expressed with different models

\begin{tabular}{|c|c|c|}
\hline Results & Linguistic & Linguistic 2-tuple \\
\hline$P S_{1}$ & ST & $($ ST,-0.0438) \\
\hline$P S_{2}$ & IM & $($ IM, +0.0250$)$ \\
\hline$P S_{3}$ & MT & $(\mathrm{MT},-0.0925)$ \\
\hline$P S_{4}$ & VLT & $(\mathrm{VLT},-0.0818)$ \\
\hline$P S_{5}$ & LT & $(\mathrm{LT},-0.1156)$ \\
\hline$P S_{6}$ & ST & $(\mathrm{ST},-0.0875)$ \\
\hline$P S_{7}$ & MT & $(\mathrm{MT},+0.0675)$ \\
\hline$P S_{8}$ & LT & $(\mathrm{LT},+0.0550)$ \\
\hline$P S_{9}$ & MT & $(\mathrm{MT},-0.0475)$ \\
\hline$P S_{10}$ & LT & $(\mathrm{LT},+0.0150)$ \\
\hline
\end{tabular}

As shown in the second column of Table 4, the results obtained by the linguistic model, which are expressed using only a set of 5 linguistic labels, can be confusing when it comes to selecting a final solution for the problem addressed here. This is due to the fact that the same linguistic label might be assigned to more than one alternative at the end of the assess- 
ment process. However, looking at the results contained in the third column, we can see how these are more varied, thanks to the use of linguistic 2-tuples. In other words, they produce better and faster decisions.

The 2-tuple linguistic representation could also result in the problem of having two different alternatives assessed with the same label, though with a much lower probability, because for two labels to match, not only the linguistic term (first component of the 2-tuple) but also the numerical value and the sign corresponding to the second term of the 2-tuple must be equal. Depending on the nature of the problem concerned, both models compared here, as well as other ones, could also be applied. However, and unlike the linguistic model and other methods, the feature commented on the linguistic 2-tuples allows us to find the most appropriate moment to launch each of the ICT products/services that a company wants to market, which is the problem that we address here.

\section{b) Sensitivity analysis of the model}

In a MCDM model, the sensitivity analysis is used to investigate the effect on the ranking of a solution if the weights of the criteria would take other possible values. Following Shih and Wu's (2015) proposal, we have proceeded to iteratively change the weights initially obtained for our case study (indicated in the Weight column of Table 3), by successively altering them with respect to a percentage of their value, and by applying our model with the new resulting weights. More specifically, we have used the following percentages for this test: $p_{1}=-5 \%, p_{2}=-10 \%, p_{3}=-15 \%, p_{4}=-15 \%$ and $p_{5}=-25 \%$. Since the initial weights are expressed in the linguistic 2-tuple model, this is equivalent to iteratively applying the process described in our model by using as new weights those resulting from applying the following formula: $\Delta\left(\Delta^{-1}(\right.$ Weight $\left.)-q_{i}\right)$, with $q_{1}=0.2, q_{2}=0.4, q_{3}=0.6, q_{4}=0.8$ and $q_{5}=1$ respectively. The results obtained are shown in Table 5, where it can be seen that the rankings have not varied at all, despite the weights having been successively modified on each application of the model. Consequently, the proposed model presents a great stability, not being sensitive to the variation in the weights initially assigned by the experts.

Table 5. Ranking of results (i.e., sorting of alternatives) according to the variation in the weights assigned to the different criteria

\begin{tabular}{|c|c|c|c|c|c|c|}
\hline Alternatives & $\begin{array}{c}\text { Original } \\
\text { weigths }\end{array}$ & $\begin{array}{c}-5 \% \text { of } \\
\text { weigths }\end{array}$ & $\begin{array}{c}-10 \% \text { of } \\
\text { weigths }\end{array}$ & $\begin{array}{c}-15 \% \text { of } \\
\text { weigths }\end{array}$ & $\begin{array}{c}-20 \% \text { of } \\
\text { weigths }\end{array}$ & $\begin{array}{c}-25 \% \text { of } \\
\text { weigths }\end{array}$ \\
\hline$P S_{1}$ & 3 & 3 & 3 & 3 & 3 & 3 \\
\hline$P S_{2}$ & 1 & 1 & 1 & 1 & 1 & 1 \\
\hline$P S_{3}$ & 4 & 4 & 4 & 4 & 4 & 4 \\
\hline$P S_{4}$ & 10 & 10 & 10 & 10 & 10 & 10 \\
\hline$P S_{5}$ & 7 & 7 & 7 & 7 & 7 & 7 \\
\hline$P S_{6}$ & 2 & 2 & 2 & 2 & 2 & 2 \\
\hline$P S_{7}$ & 6 & 6 & 6 & 6 & 6 & 6 \\
\hline$P S_{8}$ & 9 & 9 & 9 & 9 & 9 & 9 \\
\hline$P S_{9}$ & 5 & 5 & 5 & 5 & 5 & 5 \\
\hline$P S_{10}$ & 8 & 8 & 8 & 8 & 8 & 8 \\
\hline
\end{tabular}


However, although the variation in weights has no influence on the ordering or relative priority at the launch of the different products/services considered, it does influence the specific point at which the corresponding launches should be made. That is to say, given a greater variation in the weights introduced, a greater delay takes place in the time at which the different products/services must be launched, as shown in Table 6. Here, for example, we can see that, although the first product/service to be released is always $P S_{2}$, it should be launched more immediately (IM label) with the original weights, while as the weights decrease, its launch is delayed more. In fact, it even has to be launched in the short-term (ST label), although at different times (increasingly later), as indicated by the second component of the corresponding 2-tuple (see the last four columns in the row with the results obtained for $\mathrm{PS}_{2}$, in Table 6). Something similar happens with the rest of the products/services (i.e. alternatives) considered. We can therefore conclude that it is important that experts assign adequately the weights, since a variation in them has influence on the determination of the ideal moment for the launch of each product/service, as shown in Table 6.

Table 6. Linguistic 2-tuples obtained for all the alternatives according to the variation introduced in the weights

\begin{tabular}{|c|l|l|l|l|l|l|}
\hline Altern. & $\begin{array}{c}\text { Original } \\
\text { weigths }\end{array}$ & $\begin{array}{c}-5 \% \text { of } \\
\text { weigths }\end{array}$ & $\begin{array}{c}-10 \% \text { of } \\
\text { weigths }\end{array}$ & $\begin{array}{c}-15 \% \text { of } \\
\text { weigths }\end{array}$ & $\begin{array}{c}-20 \% \text { of } \\
\text { weigths }\end{array}$ & $\begin{array}{c}-25 \% \text { of } \\
\text { weigths }\end{array}$ \\
\hline$P S_{2}$ & $(\mathrm{IM},+0.0250)$ & $(\mathrm{IM},+0.0750)$ & $(\mathrm{ST},-0.1250)$ & $(\mathrm{ST},-0.0750)$ & $(\mathrm{ST},-0.0250)$ & $(\mathrm{ST},+0.0250)$ \\
\hline$P S_{6}$ & $(\mathrm{ST},-0.0875)$ & $(\mathrm{ST},-0.0375)$ & $(\mathrm{ST},+0.0125)$ & $(\mathrm{ST},+0.0625)$ & $(\mathrm{ST},+0.1125)$ & $(\mathrm{MT},-0.0875)$ \\
\hline$P S_{1}$ & $(\mathrm{ST},-0.0438)$ & $(\mathrm{ST},+0.0031)$ & $(\mathrm{ST},+0.0500)$ & $(\mathrm{ST},+0.0969)$ & $(\mathrm{MT},-0.1063)$ & $(\mathrm{MT},-0.0594)$ \\
\hline$P S_{3}$ & $(\mathrm{MT},-0.0925)$ & $(\mathrm{MT},-0.0531)$ & $(\mathrm{MT},-0.0138)$ & $(\mathrm{MT},+0.0256)$ & $(\mathrm{MT},+0.0650)$ & $(\mathrm{MT},+0.1044)$ \\
\hline$P S_{9}$ & $(\mathrm{MT},-0.0475)$ & $(\mathrm{MT},-0.0119)$ & $(\mathrm{MT},+0.0238)$ & $(\mathrm{MT},+0.0594)$ & $(\mathrm{MT},+0.0950)$ & $(\mathrm{LT},-0.1194)$ \\
\hline$P S_{7}$ & $(\mathrm{MT},+0.0675)$ & $(\mathrm{MT},+0.1025)$ & $(\mathrm{LT},-0.1125)$ & $(\mathrm{LT},-0.0775)$ & $(\mathrm{LT},-0.0425)$ & $(\mathrm{LT},-0.0075)$ \\
\hline$P S_{5}$ & $(\mathrm{LT},-0.1156)$ & $(\mathrm{LT},-0.0844)$ & $(\mathrm{LT},-0.0531)$ & $(\mathrm{LT},-0.0219)$ & $(\mathrm{LT},+0.0094)$ & $(\mathrm{LT},+0.0406)$ \\
\hline$P S_{10}$ & $(\mathrm{LT},+0.0150)$ & $(\mathrm{LT},+0.0350)$ & $(\mathrm{LT},+0.0550)$ & $(\mathrm{LT},+0.0750)$ & $(\mathrm{LT},+0.0950)$ & $(\mathrm{LT},+0.1150)$ \\
\hline$P S_{8}$ & $(\mathrm{LT},+0.0550)$ & $(\mathrm{LT},+0.0794)$ & $(\mathrm{LT},+0.1038)$ & $(\mathrm{VLT},-0.1219)$ & $(\mathrm{VLT},-0.0975)$ & $(\mathrm{VLT},-0.0731)$ \\
\hline$P S_{4}$ & $(\mathrm{VLT},-0.0819)$ & $(\mathrm{VLT},-0.0625)$ & $(\mathrm{VLT},-0.0431)$ & $(\mathrm{VLT},-0.0238)$ & $(\mathrm{VLT},-0.0044)$ & $(\mathrm{VLT},-0.0150)$ \\
\hline
\end{tabular}

\section{Conclusions and future work}

This paper presents a LMCDM model specifically designed to be applied to corporate strategic planning concerning products and services in the ICT sector, although it can also be applied to any other economic sector. Linguistic labels (expressed in natural language) are used both to express assessments and to assign the weight or importance level to each criterion involved in the evaluation of the different products or services considered in the goals to be achieved by a company within its strategic plan. In order to avoid information loss, computing with words is employed using the 2-tuple representation throughout the process. Therefore, this proposal is aimed at improving decision-making processes in corporate strategic planning, from a qualitative perspective. In other words, we avoid translating the qualitative information to quantitative information and vice versa, which involves information loss. 
For model validation and to demonstrate its efficiency, we have presented an example of an application to a specific case study concerning a telecommunications company's decisionmaking within its strategic plan. By applying the proposed model, we established the order of launch for the products and services included in the company's strategic plan and the goals set in it. The article describes how our model was applied to the selected case study and analyses the results obtained.

The goal of the work presented in this paper is to provide a sound alternative to the launch scheduling of products/services considered in the strategic planning of companies from the ICT sector that differs from the standard methodologies based on quantitative analyses. Therefore, the proposed method brings the following advantages:

- Easy assessment by the people participating in the process, thanks to the natural language used through linguistic labels, for assessing the different elements involved in the process.

- Since computing with words is applied, the transformations of qualitative to quantitative assessments are not needed, unlike other methods, thus avoiding the consequent loss of information and obtaining more precise results.

- Establishment of the importance level for every criterion considered in the areas involved, by assigning weights expressed with 2-tuple linguistic labels.

- Flexible time-frame, adapted to the specific needs of the case study at hand.

- Conversion of the linguistic labels used during the assessment of alternatives to different and more appropriate labels, to determine the ideal moment for launching each product/service assessed, within the time scale initially established in the corporate strategic planning.

On the basis of the analysis carried out and the experience acquired, we can state that the model proposed will be a positive contribution to the decision-making processes of the companies or institutions using it.

As a future line of work, we consider extending this LMCDM model by making use of new and innovative techniques, such as the intuitionist models (Peng \& Wang, 2017; Peng, Wang, \& Cheng, 2018; Yu, Wang, J., \& Wang, J. Q., 2016), as well as applying the resultant model to other economic sectors, in particular to companies or organizations that need to prioritize goals or projects to be implemented over the period of time established in their strategic planning. Without a doubt, this will have positive impacts on their subsequent decision-making processes, which will result in better and more effective strategic plans, which in turn will be reflected in their profit and loss accounts.

\section{Acknowledgements}

The authors would like to acknowledge the financial support received from the European Regional Development Fund (ERDF) for the Research Projects TIN2016-75850-R, TIN201679484-R and TIN2013-40658-P.

\section{References}

Allen, K. R. (2015). Launching new ventures: An entrepreneurial approach. Mason, OH: Cengage Learning. Barney, J. B. (2014). Gaining and sustaining competitive advantage. New York, NY: Pearson Higher Ed. 
Behzadian, M., Otaghsara, S. K., Yazdani, M., \& Ignatius, J. (2012). A state-of the-art survey of TOPSIS applications. Expert Systems with Applications, 39(17), 13051-13069.

https://doi.org/10.1016/j.eswa.2012.05.056

Benedetto, C. A. (1999). Identifying the key success factors in new product launch. Journal of Product Innovation Management, 16(6), 530-544. https://doi.org/10.1016/S0737-6782(99)00014-4

Bezdek, J. C. (2013). Pattern recognition with fuzzy objective function algorithms. Logan, UT: Springer Science \& Business Media.

Bharadwaj, A., El Sawy, O. A., Pavlou, P. A., \& Venkatraman, N. (2013). Digital business strategy: toward a next generation of insights. MIS Quarterly, 37(2), 471-482.

https://doi.org/10.25300/MISQ/2013/37:2.3

Bryson, J. M. (2011). Strategic planning for public and nonprofit organizations: A guide to strengthening and sustaining organizational achievement. Somerset, NJ: John Wiley \& Sons.

Cabrerizo, F. J., Chiclana, F., Al-Hmouz, R., Morfeq, A., Balamash, A. S., \& Herrera-Viedma, E. (2015). Fuzzy decision making and consensus: challenges. Journal of Intelligent \& Fuzzy Systems, 29(3), 1109-1118. https://doi.org/10.3233/IFS-151719

Cabrerizo, F. J., Herrera-Viedma, E., \& Pedrycz, W. (2013). A method based on PSO and granular computing of linguistic information to solve group decision making problems defined in heterogeneous contexts. European Journal of Operational Research, 230(3), 624-633.

https://doi.org/10.1016/j.ejor.2013.04.046

Cabrerizo, F. J., Ureña, M. R., Pedrycz, W., \& Herrera-Viedma, E. (2014). Building consensus in group decision making with an allocation of information granularity. Fuzzy Sets and Systems, 255, 115127. https://doi.org/10.1016/j.fss.2014.03.016

Calantone, R. J., \& Di Benedetto, C. A. (2012). The role of lean launch execution and launch timing on new product performance. Journal of the Academy of Marketing Science, 40(4), 526-538. https://doi.org/10.1007/s11747-011-0258-1

Carlsson, C., \& Fuller, R. (2002). Fuzzy reasoning in decision making and optimization. Germany, Heidelberg: Springer-Verlag. https://doi.org/10.1007/978-3-7908-1805-5

Carrasco, R. A., Muñoz-Leiva, F., Sánchez-Fernández, J., \& Liébana-Cabanillas, F. J. (2012). A model for the integration of e-financial services questionnaires with SERVQUAL scales under fuzzy linguistic modelling. Expert Systems with Applications, 39(14), 11535-11547.

https://doi.org/10.1016/j.eswa.2012.03.055

Carrasco, R. A., Sánchez-Fernández, J., Muñoz-Leiva, F., Blasco, M. F., \& Herrera-Viedma, E. (2015). Evaluation of the hotels e-services quality under the user's experience. Soft Computing, 21(4), 9951011. https://doi.org/10.1007/s00500-015-1832-0

Carrasco, R. A., Villar, P., Hornos, M. J., \& Herrera-Viedma, E. (2011). A linguistic multi-criteria decision making model applied to the integration of education questionnaires. International Journal of Computational Intelligence Systems, 4(5), 946-959. https://doi.org/10.1080/18756891.2011.9727844

Cid-López, A., Hornos, M. J., Carrasco, R. A., \& Herrera-Viedma, E. (2015a). A hybrid model for decision-making in the information and communications technology sector. Technological and Economy Development of Economy, 21(5), 731-748. https://doi.org/10.3846/20294913.2015.1056281

Cid-López, A., Hornos, M. J., Carrasco, R. A., \& Herrera-Viedma, E. (2015b). SQUAL: A fuzzy linguistic multi-criteria model to assess the quality of service in the ICT sector from the user perspective. Applied Soft Computing, 37, 897-910. https://doi.org/10.1016/j.asoc.2015.09.019

Cid-López, A., Hornos, M. J., Carrasco, R. A., \& Herrera-Viedma, E. (2016). Applying a linguistic multi-criteria decision-making model to the analysis of ICT suppliers' offers. Expert Systems with Applications, 57, 127-138. https://doi.org/10.1016/j.eswa.2016.03.025

Cid-López, A., Hornos, M. J.; Carrasco, R. A.; \& Herrera-Viedma, E., Chiclana, F. (2017). Linguistic multi-criteria decision-making model with output variable expressive richness. Expert Systems with Applications, 83, 350-362. https://doi.org/10.1016/j.eswa.2017.04.049 
Debruyne, M., Moenaert, R., Griffin, A., Hart, S., Hultink, E. J., \& Robben, H. (2002). The impact of new product launch strategies on competitive reaction in industrial markets. Journal of Product Innovation Management, 19(2), 159-170. https://doi.org/10.1016/S0737-6782(01)00135-7

Dong, Y., Li, C. C., \& Herrera, F. (2016). Connecting the linguistic hierarchy and the numerical scale for the 2-tuple linguistic model and its use to deal with hesitant unbalanced linguistic information. Information Sciences, 367, 259-278. https://doi.org/10.1016/j.ins.2016.06.003

Dong, Y., Zhang, H., \& Herrera-Viedma, E. (2016). Integrating experts' weights generated dynamically into the consensus reaching process and its applications in managing non-cooperative behaviors. Decision Support Systems, 84, 1-15. https://doi.org/10.1016/j.dss.2016.01.002

Figueira, J., Greco, S., \& Ehrgott, M. (2005). Multiple criteria decision analysis: State of the art surveys. New York, NY: Springer Science + Business Media.

Gal, T., Stewart, T., \& Hanne, T. (2013). Multicriteria decision making: Advances in MCDM models, algorithms, theory, and applications. New York, NY: Springer Science + Business Media.

Goetsch, D. L., \& Davis, S. B. (2014). Quality management for organizational excellence. Upper Saddle River, NJ: Pearson Higher Education.

Govindan, K., \& Jepsen, M. B. (2016). ELECTRE: A comprehensive literature review on methodologies and applications. European Journal of Operational Research, 250(1), 1-29. https://doi.org/10.1016/j.ejor.2015.07.019

Herrera, F., \& Martínez, L. (2000a). A 2-tuple fuzzy linguistic representation model for computing with words. IEEE Transactions on Fuzzy Systems, 8(6), 746-752. https://doi.org/10.1109/91.890332

Herrera, F., \& Martínez, L. (2000b). An approach for combining linguistic and numerical information based on the 2-tuple fuzzy linguistic representation model in decision-making. International Journal of Uncertainty, Fuzziness and Knowledge-Based Systems, 8(5), 539-562. https://doi.org/10.1142/S0218488500000381

Herrera, F., \& Martínez, L. (2001). The 2-tuple linguistic computational model: Advantages of its linguistic description, accuracy and consistency. International Journal of Uncertainty, Fuzziness and Knowledge-Based Systems, 9(supp01), 33-48. https://doi.org/10.1142/S0218488501000971

Herrera, F., Alonso, S., Chiclana, F., \& Herrera-Viedma, E. (2009). Computing with words in decision making: foundations, trends and prospects. Fuzzy Optimization and Decision Making, 8(4), 337-364. https://doi.org/10.1007/s10700-009-9065-2

Herrera, F., Herrera-Viedma, E., \& Martínez, L. (2008). A fuzzy linguistic methodology to deal with unbalanced linguistic term sets. IEEE Transactions on Fuzzy Systems, 16(2), 354-370. https://doi.org/10.1109/TFUZZ.2007.896353

Howard, A. F. (1991). A critical look at multiple criteria decision making techniques with reference to forestry applications. Canadian Journal of Forest Research, 21(11), 1649-1659. https://doi.org/10.1139/x91-228

IBM (n. d.). SPSS Modeler. Retrieved from https://www.ibm.com/products/spss-modeler

Kacprzyk, J., \& Fedrizzi, M. (1990). Multiperson decision making models using fuzzy sets and possibility theory. The Netherlands, Dordrecht: Kluwer Academic Publishers. https://doi.org/10.1007/978-94-009-2109-2

Kacprzyk, J., \& Zadrozny, S. A. (2001). Computing with words in decision making through individual and collective linguistic choice rules. International Journal of Uncertainty, Fuzziness and KnowledgeBased Systems, 9(supp01), 89-102. https://doi.org/10.1142/S0218488501001010

Kahn, K. B., Barczak, G., Nicholas, J., Ledwith, A., \& Perks, H. (2012). An examination of new product development best practice. Journal of Product Innovation Management, 29(2), 180-192. https://doi.org/10.1111/j.1540-5885.2011.00888.x

Kao, C., \& Liu, S. T. (2001). Fractional programming approach to fuzzy weighted average. Fuzzy Sets and Systems, 120(3), 435-444. https://doi.org/10.1016/S0165-0114(99)00137-2 
Kapferer, J. N. (2012). The new strategic brand management: Advanced insights and strategic thinking. London, UK: Kogan Page.

Kaplan, R. S., \& Norton, D. P. (2001). The strategy focused organization: How balanced scorecard companies thrive in the new business environment. Boston, MA: Harvard Business Press,

Kolios, A., Mytilinou, V., Lozano-Minguez, E., \& Salonitis, K. (2016). A comparative study of multiplecriteria decision-making methods under stochastic inputs. Energies, 9(7), 566. https://doi.org/10.3390/en9070566

Kou, G., Lu, Y., Peng, Y., \& Shi, Y. (2012). Evaluation of classification algorithms using MCDM and rank correlation. International Journal of Information Technology \& Decision Making, 11(01), 197-225. https://doi.org/10.1142/S0219622012500095

Li, C. C., Dong, Y., Herrera, F., Herrera-Viedma, E., \& Martínez, L. (2017). Personalized individual semantics in computing with words for supporting linguistic group decision making. An application on consensus reaching. Information Fusion, 33, 29-40. https://doi.org/10.1016/j.inffus.2016.04.005

Liao, H., \& Xu, Z. (2015). Approaches to manage hesitant fuzzy linguistic information based on the cosine distance and similarity measures for HFLTSs and their application in qualitative decision making. Expert Systems with Applications, 42(12), 5328-5336. https://doi.org/10.1016/j.eswa.2015.02.017

Liou, J., \& Tzeng, G. H. (2012). Comments on "Multiple criteria decision making (MCDM) methods in economics: an overview". Technological and Economic Development of Economy, 18(4), 672-695. https://doi.org/10.3846/20294913.2012.753489

Liu, W., Dong, Y., Chiclana, F., Cabrerizo, F. J., \& Herrera-Viedma, E. (2017). Group decision-making based on heterogeneous preference relations with self-confidence. Fuzzy Optimization and Decision Making, 16, 429-447. https://doi.org/10.1007/s10700-016-9254-8

Ma, Y. X., Wang, J., Wang, J. Q., \& Chen, X. H. (2016). Two-tuple linguistic aggregation operators based on subjective sensation and objective numerical scales for multi-criteria group decision-making problems. Scientia Iranica. Transactions E: Industrial Engineering, 23(3), 1399-1417. https://doi.org/10.24200/sci.2016.3906

Mardani, A., Jusoh, A., \& Zavadskas, E. K. (2015). Fuzzy multiple criteria decision-making techniques and applications -Two decades review from 1994 to 2014. Expert Systems with Applications, 42(8), 4126-4148. https://doi.org/10.1016/j.eswa.2015.01.003

Martínez, L. (2007). Sensory evaluation based on linguistic decision analysis. International Journal of Approximate Reasoning, 44(2), 148-164. https://doi.org/10.1016/j.ijar.2006.07.006

Martínez-Cruz, C., Porcel, C., Bernabé-Moreno, J., \& Herrera-Viedma, E. (2015). A model to represent users trust in recommender systems using ontologies and fuzzy linguistic modeling. Information Sciences, 311, 102-118. https://doi.org/10.1016/j.ins.2015.03.013

Massanet, S., Riera, J. V., Torrens, J., \& Herrera-Viedma, E. (2014). A new linguistic computational model based on discrete fuzzy numbers for computing with words. Information Sciences, 258, 277290. https://doi.org/10.1016/j.ins.2013.06.055

Mendel, J. M. (2007a). Computing with words and its relationships with fuzzistics. Information Sciences, 177(4), 988-1006. https://doi.org/10.1016/j.ins.2006.06.008

Mendel, J. M. (2007b). Computing with words: Zadeh, Turing, Popper and Occam. IEEE Computational Intelligence Magazine, 2(4), 10-17. https://doi.org/10.1109/MCI.2007.9066897

Meyr, H., Wagner, M., \& Rohde, J. (2015). Structure of advanced planning systems: Supply chain management and advanced planning. Germany, Heidelberg: Springer. https://doi.org/10.1007/978-3-642-55309-7_5

Morente-Molinera, J. A., Mezei, J., Carlsson, C., \& Herrera-Viedma, E. (2017). Improving supervised learning classification methods using multi-granular linguistic modelling and fuzzy entropy. IEEE Transactions on Fuzzy Systems, 25, 1078-1089. 
Morente-Molinera, J. A., Pérez, I. J., Ureña, M. R., \& Herrera-Viedma, E. (2015). On multi-granular fuzzy linguistic modeling in group decision making problems: A systematic review and future trends. Knowledge-Based Systems, 74, 49-60. https://doi.org/10.1016/j.knosys.2014.11.001

Peng, H. G., \& Wang, J. Q. (2017). Cloud decision model for selecting sustainable energy crop based on linguistic intuitionistic information. International Journal of Systems Science, 48(15), 3316-3333. https://doi.org/10.1080/00207721.2017.1367433

Peng, H. G., Wang, J. Q., \& Cheng, P. F. (2018). A linguistic intuitionistic multi-criteria decision-making method based on the Frank Heronian mean operator and its application in evaluating coal mine safety. International Journal of Machine Learning and Cybernetics 9(6), 1053-1068. https://doi.org/10.1007/s13042-016-0630-z.

Pérez, I. J., Cabrerizo, F. J. \& Herrera-Viedma, E. (2010). A mobile decision support system for dynamic group decision making problems. IEEE Transactions on Systems, Man and Cybernetics - Part A: Systems and Humans, 40, 1244-1256. https://doi.org/10.1109/TSMCA.2010.2046732

Pérez, I. J., Cabrerizo, F. J., Alonso, S., \& Herrera-Viedma, E. (2014). A new consensus model for group decision making problems with non-homogeneous experts. IEEE Transactions on Systems, Man, and Cybernetics: Systems, 44(4), 494-498. https://doi.org/10.1109/TSMC.2013.2259155

Pérez-Asurmendi, P., \& Chiclana, F. (2014). Linguistic majorities with difference in support. Applied Soft Computing, 18, 196-208. https://doi.org/10.1016/j.asoc.2014.01.010

Shih, H. S., \& Wu, W. P. (2015). A formulation of DM's risk attitude in ELECTRE III. In $81^{\text {st }}$ Meeting of the European Working Group-Multiple Criteria Decision Aiding (No. mcda81). Retrieved from http://spirit.tku.edu.tw:8080/phd/upload/603620070/\%B5o\%AA\%ED\%BD\%D7\%A4\%E5\%A5\%FE \%A4\%E5.pdf

Thor, J., Ding, S. H., \& Kamaruddin, S. (2013). Comparison of multi criteria decision making methods from the maintenance alternative selection perspective. The International Journal of Engineering and Science, 2(6), 27-34.

Tong, R. M., \& Bonissone, P. P. (1980). A linguistic approach to decision making with fuzzy sets. IEEE Transactions on Systems, Man, and Cybernetics, 10(11), 716-723. https://doi.org/10.1109/TSMC.1980.4308391

Triantaphyllou, E. (2013). Multi-criteria decision making methods: A comparative study. Logan, UT: Springer Science \& Business Media.

Tscheikner-Gratl, F., Egger, P., Rauch, W., \& Kleidorfer, M. (2017). Comparison of multi-criteria decision support methods for integrated rehabilitation prioritization. Water, 9(2), 68. https://doi.org/10.3390/w9020068

Tzeng, G. H., \& Huang, J. J. (2011). Multiple attribute decision making: Methods and applications. Boca Raton, FL: CRC Press.

Wang, J., Wang, J. Q., Tian, Z. P., \& Zhao, D. Y. (2017). A multihesitant fuzzy linguistic multicriteria decision-making approach for logistics outsourcing with incomplete weight information. International Transactions in Operational Research 25(3), 831-856. https://doi.org/10.1111/itor.12448

Wang, J. Q., Peng, J. J., Zhang, H. Y., Liu, T., \& Chen, X. H. (2015). An uncertain linguistic multi-criteria group decision-making method based on a cloud model. Group Decision and Negotiation, 24(1), 171-192. https://doi.org/10.1007/s10726-014-9385-7

Winter, S., \& Sundqvist, S. (2009). IMC strategies in new high technology product launches. Marketing Intelligence \& Planning, 27(2), 191-215. https://doi.org/10.1108/02634500910944986

Wu, J., Chiclana, F., \& Herrera-Viedma, E. (2015). Trust based consensus model for social network in an incomplete linguistic information context. Applied Soft Computing, 35, 827-839. https://doi.org/10.1016/j.asoc.2015.02.023

$\mathrm{Xu}, \mathrm{Z}$. (2015). Uncertain multi-attribute decision making: Methods and applications. Germany, Heidelberg: Springer. https://doi.org/10.1007/978-3-662-45640-8 
Yager, R. R. (1988). On ordered weighted averaging aggregation operators in multicriteria decision making. IEEE Transactions on Systems Man and Cybernetics, 18(1), 183-190. https://doi.org/10.1109/21.87068

Yager, R. R. (1993). Families of OWA Operators. Fuzzy Sets and Systems, 59(2), 125-148. https://doi.org/10.1016/0165-0114(93)90194-M

Yager, R. R. (1994a). Interpreting linguistically quantified propositions. International Journal of Intelligent Systems, 9(6), 541-569. https://doi.org/10.1002/int.4550090604

Yager, R. R. (1994b). On weighted median aggregation. International Journal of Uncertainty, Fuzziness and Knowledge-Based Systems, 2(01), 101-113. https://doi.org/10.1142/S0218488594000092

Yager, R. R. (2007). Aggregation of ordinal information. Fuzzy Optimization and Decision Making, 6(3), 199-219. https://doi.org/10.1007/s10700-007-9008-8

Yager, R.R., \& Filev, D. P. (1999). Induced ordered weighted averaging operators. IEEE Transactions on Systems, Man, and Cybernetics, Part B: Cybernetics, 29(2), 141-150. https://doi.org/10.1109/3477.752789

Yu, S. M., Wang, J., \& Wang, J. Q. (2016). An extended TODIM approach with intuitionistic linguistic numbers. International Transactions in Operational Research 25(3), 781-805. https://doi.org/10.1111/itor.12363.

Yu, S. M., Wang, J., Wang, J. Q., \& Li, L. (2017). A multi-criteria decision-making model for hotel selection with linguistic distribution assessments. Applied Soft Computing 67, 741-755. https://doi.org/10.1016/j.asoc.2017.08.009

Zadeh, L. A. (1983). A computational approach to fuzzy quantifiers in natural languages. Computers \& Mathematics with Applications, 9(1), 149-184. https://doi.org/10.1016/0898-1221(83)90013-5

Zadeh, L. A. (1996). Fuzzy logic = computing with words. IEEE Transactions on Fuzzy Systems 4(2), 103-111. https://doi.org/10.1109/91.493904

Zavadskas, E. K., \& Turskis, Z. (2011). Multiple criteria decision making (MCDM) methods in economics: an overview. Technological and Economic Development of Economy, 17(2), 397-427. https://doi.org/10.3846/20294913.2011.593291

Zavadskas, E. K., Turskis, Z., \& Kildienė, S. (2014). State of art surveys of overviews on MCDM/MADM methods. Technological and Economic Development of Economy, 20(1), 165-179. https://doi.org/10.3846/20294913.2014.892037

Zhang, H., Dong, Y., \& Herrera-Viedma, E. (2017). Consensus building for the heterogeneous largescale GDM with the individual concerns and satisfactions. IEEE Transactions on Fuzzy Systems, 26(2), 884-898. https://doi.org/10.1109/TFUZZ.2017.2697403 


\section{APPENDIX 1}

\section{Comparison of the main MCDM methods for the solution of discrete problems}

Based on the comparison set forth by Thor, Ding, and Kamaruddin (2013), some of the main MCDM methods are evaluated in this appendix, taking into account the product launch planning problem addressed in this article. More specifically, AHP, ELECTRE, SAW and TOPSIS are evaluated and compared according to different elements or dimensions, which are: core process, problem structure, concept, consistency and final results. Table 1A shows the characteristics of each of these models with respect to such dimensions.

Table 1A. Comparison of AHP, ELECTRE, SAW and TOPSIS according to Thor et al. (2013)

\begin{tabular}{|l|l|l|l|l|}
\hline Element $\backslash$ Method & \multicolumn{1}{|c|}{ AHP } & \multicolumn{1}{|c|}{ ELECTRE } & \multicolumn{1}{c|}{ SAW } & \multicolumn{1}{c|}{ TOPSIS } \\
\hline Core process & $\begin{array}{l}\text { Hierarchy } \\
\text { principle }\end{array}$ & $\begin{array}{l}\text { Pairwise } \\
\text { comparison } \\
\text { principle }\end{array}$ & $\begin{array}{l}\text { Weighted average } \\
\text { principle }\end{array}$ & Distance principle \\
\hline Problem structure & $\begin{array}{l}\text { Few criteria and } \\
\text { alternatives }\end{array}$ & Many criteria & $\begin{array}{l}\text { Many criteria and } \\
\text { alternatives }\end{array}$ & $\begin{array}{l}\text { Many criteria and } \\
\text { alternatives }\end{array}$ \\
\hline Concept & Scoring model & $\begin{array}{l}\text { Concordance } \\
\text { model }\end{array}$ & Scoring model & $\begin{array}{l}\text { Compromising } \\
\text { model }\end{array}$ \\
\hline Consistency & Yes & Yes & No & No \\
\hline Final Results & $\begin{array}{l}\text { Global, net } \\
\text { ordering }\end{array}$ & Partial pre-order & $\begin{array}{l}\text { Global, net } \\
\text { ordering }\end{array}$ & $\begin{array}{l}\text { Global, net } \\
\text { ordering }\end{array}$ \\
\hline
\end{tabular}

According to the analysed elements, we find that each method has its specificity, which is very determinant when choosing the most adequate model to be applied to the resolution of a given problem, for which it is necessary to take into account not only the own nature of the problem, but also the type of data to be managed, as well as its quantity and variety, as indicated by Tscheikner-Gratl, Egger, Rauch, and Kleidorfer (2017).

Analysing the Core process element, we see that each of the evaluated methods uses a different principle. Thus:

- AHP uses the hierarchy principle and pairwise comparison matrices to select the obtained rankings of alternatives. The advantages of this method are the possibility to use both qualitative and quantitative criteria, the ordered fashion of the decision making, which allows a good traceability of the decision, and the quality assurance given by the consistency indices.

- ELECTRE focuses on the pairwise comparison principle by using concordance and discordance indexes.

- SAW applies the weighted average principle by assigning a scale value to each alternative.

- TOPSIS utilises the distante principle by calculating the shortest distance of an alternative from the positive ideal solution and the longest distance from the negative ideal solution. 
In our case, due to the particularities of the problem to be solved, in which we have a group of criteria with sub-criteria, the core process of the SAW method is the most appropriate to address our problem, since starting from the preferences initially assigned to each area, collective preferences are obtained without loss of information. This would not be achieved with the other methods. As said in the article, the use of linguistic information to express preferences does not imply any loss of precision, thanks to the use of the 2-tuple linguistic model (Herrera \& Martínez, 2001, 2000a). Moreover, the SAW method is formulated for problems in which all variables have the same physical dimensions, being based on the "additive utility" assumption (Triantaphyllou, 2013). However, it still provides similar results when compared with more sophisticated methods according to Kolios et al. (2016).

Regarding the Problem structure element, we note that AHP and ELECTRE do not meet our requirements, since our proposal is aimed at solving problems that contain many criteria and many alternatives.

As for the Concept element, ELECTRE and TOPSIS do not conform to the requirements of the problem to be addressed, since it is necessary that each alternative has a score so that it can be subsequently extrapolated to a time scale.

In the case of the Consistency element, the SAW method, due to its nature, has the worst behaviour in this dimension. Nonetheless, we have included a sensitivity analysis (see Section 3.3) in the proposal made, which allows us to determine the need for the experts to be able to assign the weights appropriately, since the weight variation, although it does not change the order of the alternatives, does influence the final result.

Finally, with respect to the Final results element, it can be observed that:

- AHP has certainly loss of information, due to potential compensation effects between good scores on some criteria and bad scores on others, as well as the complex and time-consuming implementation, depending on the number of criteria and alternatives (Mardani, Jusoh, \& Zavadskas, 2015).

- ELECTRE does not serve for our purpose, since it aims is to select a small set of the best alternatives, but not to construct an ordered list of the alternatives evaluated, from the best to the worst (Govindan \& Jepsen, 2016).

- TOPSIS adopts a compromise solution to choose the best alternative, which is the one that is nearest to the positive ideal solution (optimal solution) and farthest from the negative ideal solution (inferior solution) (Behzadian et al., 2012).

- SAW chooses as the optimal alternative the closest one to the "best" value. This value contains the maximum of all criteria (Kolios et al., 2016). Moreover, as mentioned when analysing the Core process element, the use of a 2-tuple linguistic model in our proposal implies obtaining results without loss of information. 